\title{
O PLIOCÉNICO DE POMBAL (BACIA DO MONDEGO, PORTUGAL OESTE): BIOSTRATIGRAFIA, PALEOECOLOGIA E PALEOBIOGEOGRAFIA
}

\author{
FILOMENA DINIZ $^{(1)}$, CARLOS MARQUES DA SILVA ${ }^{(2)} \&$ MÁRIO CACHÃO ${ }^{(3)}$
}

Resumo:

\begin{abstract}
No presente trabalho são apresentados dados palinológicos inéditos da importante sequência do Pliocénico português em Pombal. Em paralelo, conjugando os dados dos vários proxies paleontológicos estudados nesta sequência, é feito o ponto da situação do conhecimento sobre nanofósseis calcários e associações de fósseis de moluscos, nomeadamente no que concerne ao seu significado biostratigráfico, paleoecológico e paleobiogeográfico. No tocante à Palinologia, a investigação dos níveis fossilíferos do Pliocénico da região em estudo evidencia uma microflora de carácter mesófilo. A presença de Taxodiaceae substituindo táxones mais termófilos como Cyrillaceae / Clethraceae indicaria descida da temperatura relativamente ao Zancleano, bem patente na sequência de Rio Maior. Na secção média da camada lignitosa (sondagem P1) a presença de Symplocos, táxon megamesotérmico, pressupõe uma ligeira subida de temperatura. O estudo palinológico da sequência representada na sondagem F58 da Bacia de Rio Maior demonstra que ela abrange o Zancleano e o Placenciano; a microflora de Pombal aqui descrita e discutida é correlacionável com o topo do conjunto esporo-polínico F da referida sequência, posicionando-se no topo do Zancleano ou na metade inferior do Placenciano ante 3,0 Ma. Em termos do significado das associações de nanofósseis calcários ricas em Coccolithus pelagicus s.l. é proposta uma interpretação, não baseada em condições paleoambientais subpolares oceânicas, mas sim em condições de afloramento costeiro (de upwelling) persistente e maior paleoprodutividade oceânica ao largo da costa ocidental da Ibéria de então. A associação de moluscos gastrópodes indica ambiente marinho pouco profundo, de salinidade normal e temperaturas subtropicais. Esta associação de gastrópodes sugere correlação com a Mediterranean Pliocene Molluscan Unit 1 do Mediterrânico, i.e., com uma idade pliocénica ante 3,0 Ma. A conjugação dos dados dos nanofósseis calcários e dos moluscos sugere para os níveis fossilíferos marinhos pliocénicos da região de Pombal um posicionamento cronostratigráfico abrangendo desde o topo do Zancleano até à metade inferior do Placenciano, desde cerca dos 3,703,61 Ma aos 3,0 Ma, ou mesmo apenas até aos 3,52 Ma, se se tiverem em conta dados dados isotópicos de ${ }^{87} \mathrm{Sr}{ }^{86} \mathrm{Sr}$.

Palavras-chave: Pliocénico, Pombal, Portugal, Palinologia, nanofósseis calcários, moluscos gastrópodes, biostratigrafia, paleoecologia, paleobiogeografia.
\end{abstract}

Abstract:

The Pliocene of the Pombal region (Mondego Basin, western Portugal): biostratigraphy, palaeoecology and palaeobiogeography

This work reports new palynological data from the important Portuguese Pliocene sedimentary sequence of Pomba (central West Portugal). Simultaneously, fusing the data from all the a proxies studied from that sequence, the state of the art of the knowledge on calcareous nannofossils and gastropod molluscs, namely concerning their biostratigraphic, palaeoecological and palaeobiogeographical meanings is presented. Regarding the palynological aspects, the upper Pliocene assemblages of the study area show a mesophile microflora. The presence of taxa such as Taxodiaceae replacing older thermophilic ones such as Cyrillaceae/Clethraceae suggests a drop in temperature in comparison with the lower Pliocene, well recorded in the Rio Maior sequence. In the middle section of the lignite beds (recorded in borehole P1 in the study area) the presence of Symplocos - a mega-mesothermic taxon -, suggests a rise in temperature. The palynological study of the sequence recorded in borehole F58 of the Rio Maior Basin demonstrates that it encompasses the entire Zanclean and Piacenzian; the microflora of Pombal herein described and discussed is correlated with the top of the spores and pollens assemblage $F$ of the Rio Maior sequence, with an uppermost Zanclean to lower Piacenzian, pre-3.0 Ma, age. Initially considered an evidence for oceanic subpolar water masses off Portugal during the deposition of the upper Pliocene Carnide Formation, the particularly abundant placoliths of Coccolithus pelagicus s.l. are reinterpreted as related to higher palaeoproductivity due to persistent upwelling conditions off the West Iberian coast at that time. The molluscan assemblage present in the study sequence indicates a shallow marine environment with normal marine salinity conditions and subtropical temperatures under the influence of coastal upwelling conditions. The gastropod assemblage is correlated with the Mediterranean Pliocene Molluscan Unit 1, dated as Pliocene pre-3.0 Ma. The conjugation of the calcareous nannofossils and the molluscan biostratigraphical data suggests for the Pliocene marine fossiliferous beds of the Pombal region a uppermost Zanclean to lower Piacenzian chronostratigraphic position, circa 3.70-3.61 to 3.0 Ma in age, or even just to $3.52 \mathrm{Ma}$, if we take in consideration the available ${ }^{87} \mathrm{Sr}{ }^{86} \mathrm{Sr}$ isotopic data.

Keywords: Pliocene, Pombal, Portugal, Palynology, calcareous nannofossils, gastropod molluscs, biostratigraphy, palaeoecology, palaeobiogeography.

Received: 24 March, 2016; Accepted: 26 April, 2016

\section{INTRODUÇÃO}

$\mathrm{Na}$ Orla Ocidental centro ibérica estão concentrados, em bacias litorais ou zonas de transição, sedimentos palustres e marinhos cuja deposição se relaciona, em regra, com o ciclo sedimentar que ocorreu durante o Cenozóico superior. As sequên- cias sedimentares atribuídas ao Pliocénico desenvolvem-se essencialmente na Orla Ocidental e na Bacia do Baixo Tejo e são constituídas por sedimentos de fácies marinhas e por sequências continentais ricas de macrorrestos vegetais (RIBEIRO et al. 1979; DINIZ 1984a).

\footnotetext{
${ }^{(1)}$ Departamento de Geologia da Faculdade de Ciências da Universidade de Lisboa e Museu Nacional de História Natural e da Ciência, fdiniz@fc.ul.pt

(2) Instituto Dom Luiz de geociências e Departamento de Geologia da Faculdade de Ciências, Universidade de Lisboa, cmsilva@fc.ul.pt

${ }^{(3)}$ Instituto Dom Luiz de geociências e Departamento de Geologia da Faculdade de Ciências, Universidade de Lisboa, mcachao@fc.ul.p
} 
Na região de Pombal, a sequência marinha fossilífera, em posição sub-horizontal, aflora de maneira descontínua no vale da Ribeira de Carnide (Carnide de Cima, Igreja de Carnide, Vale Bouchada, Vale Farpado e Vale de Cabra), a $110 \mathrm{~m}$ de altitude. Trata-se de conglomerados fossilíferos a que se sobrepõem arenitos finos a médios, argilosos, ricos de somatofósseis, sobretudo, de bivalves, gastrópodes, crustáceos cirrípedes e briozoários, formando lumachela. A malacofauna foi inicialmente estudada por Teixeira \& Zbyszewski (1951) e Manupela et al. (1978). Segundo Carvalho (1971), a associação de briozoários de Pombal e de Caldas da Rainha traduz o carácter litoral dos depósitos e sugere que a temperatura das águas era um pouco mais elevada que a actual àquela latitude; as associações identificadas demonstram que a costa portuguesa no Pliocénico era uma zona de interpenetração de faunas mediterrânicas e atlânticas. O estudo de foraminíferos e ostracodos abona também a favor de um ambiente litoral pouco profundo e de águas mais quentes que na actualidade (ROCHA \& FERREIRA 1953; CARVALHO \& COlOM 1954; FERREIRA 1960; CARdoso 1984). Os dados do estudo dos fósseis de moluscos são apresentados abaixo, em "Malacofauna pliocénica: ponto da situação".

A posição biostratigráfica destas jazidas foi estabelecida por Carla Müller com base no estudo de nanofósseis calcários provenientes de uma amostra de sedimento recolhida em 1980 por João Cardoso nos níveis fossilíferos de Vale Farpado. A associação identificada indicou posicionamento na biozona NN16 a NN18 de Martini (1971), actualmente correspondendo ao intervalo abrangendo, grosso modo, desde o topo do Zancleano ao topo do Gelasiano (in DINIZ 1984a; posicionamento das biozonas NN16 a NN18 segundo BACKMAN et al. 2012).

No vale da Ribeira de Carnide foram também assinalados restos de vegetais fósseis em Regato, Beijouca e Carnide de Cima. Em Alto dos Crespos e Vale Coimbra, à cota 140-150 m, ocorrem depósitos continentais (argilas amareladas, grés e areias) em posição sub-horizontal. Observam-se nas mesmas localidades, intercaladas nas argilas, camadas lignitosas ricas de madeira fóssil (Outeiro da Ranha) ou mesmo lignitos com troncos fossilizados e diatomitos (Alto dos Crespos). Por outro lado, sondagens realizadas em Matos da Ranha, atravessaram madeira fóssil, lignitos e diatomitos lignitosos; trata-se de camadas mais ou menos argilosas, intercaladas em grés (ZBYSZEWSKI \& FARIA 1971).

A sucessão de Pombal culmina numa superfície aplanada coberta por areias com elementos bem rolados situada à altitude de $178 \mathrm{~m}$ em Areeiro e de 185 m em Palão (TEIXEIRA \& ZBYSZEVSKI 1951; TEIXEIRA 1979).

A descoberta em 1980 da jazida fossilífera de Vale do Freixo em Carnide (Fig. 1) num barreiro abandonado abriu novas perspectivas de estudo, permitindo o recurso a metodologias distintas.

$\mathrm{O}$ estudo de três proxies distintos (pólenes, nanofósseis calcários, moluscos), abrangendo aspectos paleobiológicos, paleoecológicos e paleoclimáticos, permitiu obter registos importantes para a reconstituição paleoambiental da fachada atlântica ibérica durante o Cenozóico superior.

\section{PALINOLOGIA}

\subsection{Paleoecossistemas, palinostratigrafia e climatostratigrafia}

Os estudos palinológicos incidiram, por um lado, nas lumachelas de Vale do Freixo, Vale Bouchada e Vale Farpado e, por outro, em sondagens implantadas entre as localidades de Alto dos Crespos e Vale Coimbra (Fig. 1), aqui designadas por sondagens de Pombal.

Vale do Freixo (UTM 25 S NE 2315015175). Esta jazida situa-se a cerca de $450 \mathrm{~m}$ a SW da Igreja de Carnide. A camada fossilífera lenticular é constituída por conglomerado cinzento rico de fósseis de moluscos a que se sobrepõem areias acinzentadas e acastanhadas com abundante malacofauna, briozoários, etc. VFX C12/3 - amostra colhida no corte 12 , no topo da camada fossilífera arenosa, de 0,25 $\mathrm{m}$ de espessura; o estudo de nanofósseis calcários da mesma camada (amostra VF 37) permitiu o posicionamento na biozona de Discoaster tamalis (CACHÃO 1989, 1990).

Vale Bouchada (UTM 29 S NE 2210015225). Nas margens de Vale Bouchada o nível fossilífero ocorre em pequenas lentículas pouco espessas a $110 \mathrm{~m}$ de altitude; observa-se por vezes a variação lateral para arenito grosseiro. VB C2/1 - no corte C2 a camada fossilífera está intercalada entre as argilas silto-arenosas miocénicas e os arenitos da Formação de Carnide; a amostra foi colhida na parte média do nível rico de bioclastros com $0,25 \mathrm{~cm}$ de espessura; foi registada abundância de Coccolithus pelagicus s.l. através do estudo de nanofósseis calcários provenientes desta camada (amostra VB 5). VB 5/2 - a amostra foi colhida no nível arenoso que corresponde a uma variação lateral da camada fossilífera.

Vale Farpado (UTM 29 S NE 2125016300). As camadas fossilíferas afloram na margem direita do vale a NW da aldeia de Vale de Cabra. É constituído por lumachela compacta de cimento argiloso rica de fósseis de conchas de bivalves e gastrópodes sobreposta a um conglomerado com clastos e conchas assente em siltitos argilosos esverdeados (CARdoso 1984). VF JC/3 - esta amostra é proveniente da referida lumachela; deve-se a Carla Müller (in DINIZ, 1984a), o estudo dos nanofósseis provenientes desta amostra. As colunas litostratigráficas da sequência fossilífera da Formação de Carnide em Vale Bouchada e em Vale do Freixo podem ser encontradas, e.g., em Cachão (1989) e Silva et al. (2010), respectivamente. 


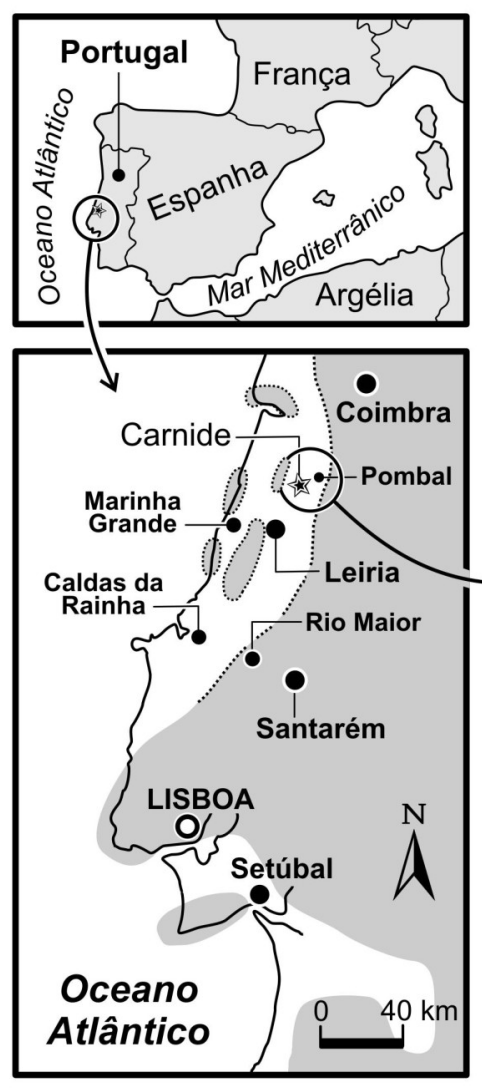

$\therefore \cdots . . . *$ - Linha de costa pliocénica

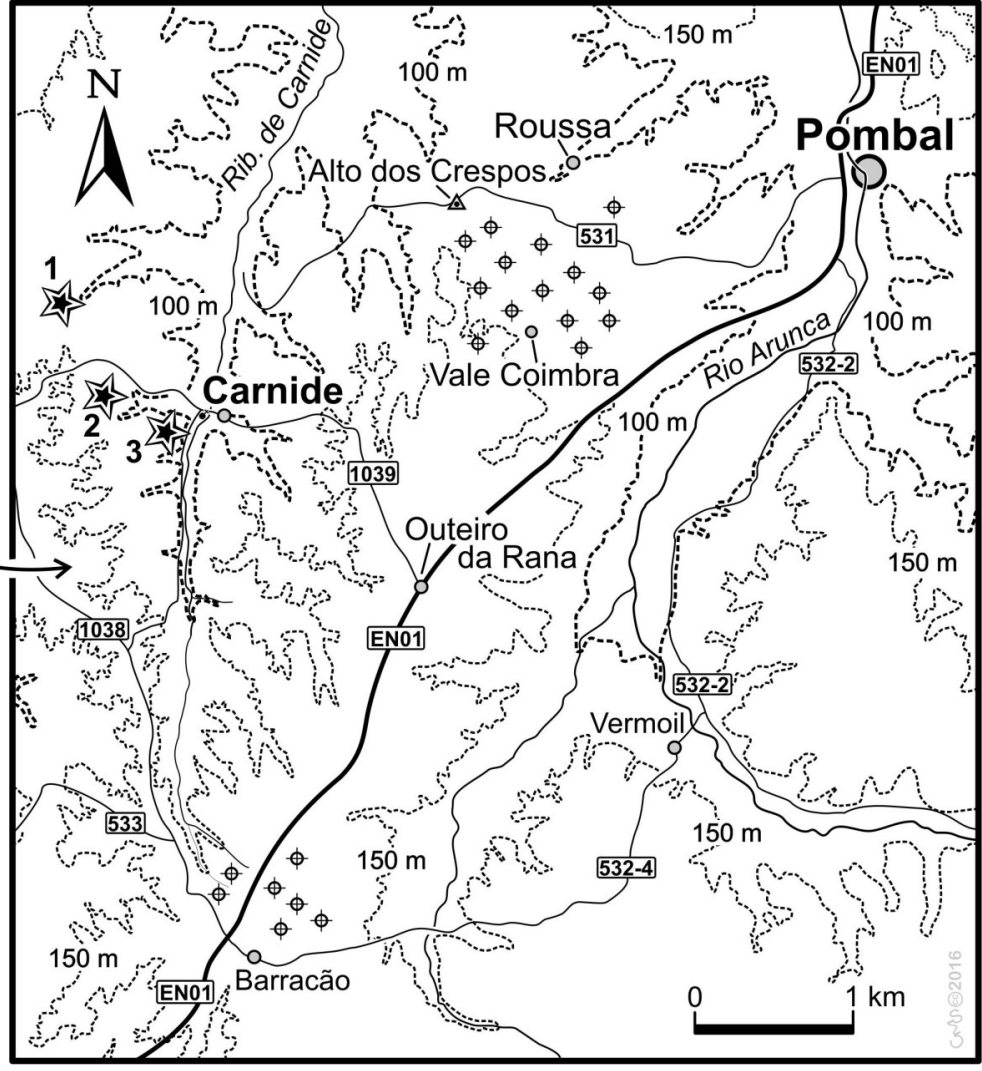

$\phi$ - Sondagens - Locais de estudo mencionados no texto

Fig. 1. Localização geográfica da região em estudo, Pombal - Carnide (Portugal centro-Oeste). Linha de costa pliocénica na região de Coimbra - Rio Maior baseada em CACHÃo \& Silva (2000). Estrelas: 1 - Vale Farpado, 2 - Vale Bouchada, 3 - Vale do Freixo. Fig. 1. Geographical location of the study area, Pombal - Carnide (west Central Portugal). Pliocene coast line in the Coimbra - Rio Maior area after CACHÃO \& SILVA (2000). Stars: 1 - Vale Farpado, 2 - Vale Bouchada, 3 - Vale do Freixo.

Foram preparadas 25 amostras provenientes destas jazidas. Apenas oito se revelaram férteis em pólen, das quais quatro foram consideradas neste trabalho por serem as mais ricas (VFX C12/3; VB C2/1 e VB C5/2; VF JC/3). Da análise dos resultados palinológicos (Tabs. 1-2; Figs. 2-3) conclui-se que os espectros polínicos de Vale do Freixo (VFX), Vale Bouchada (VB) e Vale Farpado (VF) são muito próximos.

De um modo geral Pinus é o táxon dominante, seguido de Quercus e Taxodiaceae, a presença de Cathaya é bastante regular. Myrica está bem representada em Vale Bouchada; tipo Castanea é constante, embora com fracas percentagens. Alnus atinge $3 \%$. Palmae sempre presente, realiza no máximo $1 \%$. Em função de critérios térmico e higrométrico foram estabelecidos sete grupos para a sequência polínica da Bacia de Rio Maior. Táxones de clima quente e húmido totalizam 6 a 13\%; Taxodiaceae (1 a 7,5\%) na maioria representados por Sequoia; Myrica alcança 6\%, decrescendo para 1,5\%; Palmae sempre presente, apenas com 1\%; Cyrillaceae/ Clethraceae e Sapotaceae são raros, com 1\%. Microtropis fallax é vestigial. Táxones de clima temperado variam entre 13 a $16 \%$; boa representação de Quercus, oscilando de 6 a 10\%, tipo Casta- nea também constante, variando de 1 a $2 \%$, seguido de Alnus, que pode atingir 3\%. Os restantes constituintes deste grupo aparecem esporadicamente e em baixos teores marcando no entanto presença. Gimnospérmicas oscilam entre 41 e $66 \%$. Pinus é o elemento dominante (36 a 61\%); Cathaya varia de 3 a 7\%; Cedrus, Tsuga e Abies são raros e vestigiais. Táxones mediterrânicos oscilam entre 1,6 a $18 \%$. Olea alcança valores significativos (3 a 6\%); Quercus ilex atinge $12 \%$, passando a vestigial, bem como outros elementos deste grupo. Cupressaceae aparece apenas em Vale Farpado, com 1\%. Herbáceas variam de 6 a 9\%; são de referir Amaranthaceae / Chenopodiaceae com 3\% e Cyperaceae com 4\% em Vale Bouchada. Ericaceae oscilam entre 1 e 16\%.

Estas, bem como a maioria das amostras provenientes das jazidas marinhas de Pombal, contêm nanofósseis calcários que foram estudados a partir do final da década de 1980 por Cachão (1989). A presença de quistos de dinoflagelados é também frequente; a identificação de vários táxones em Vale do Freixo sugere que os níveis fossilíferos se formaram em ambiente marinho pouco profundo com influência salobra (presença de Selenopemphix armageddonensis e de Lingulodinium machaerophorum) e com águas de temperatura elevada compro- 
vada pela ocorrência de espécies termófilas como Tectatodinium pellitum e Lingulodininium machaerophorum (VIEIRA el al. 2006; VIEIRA 2009). Estes resultados, grosso modo, ressalvando a referência a influência salobra, são coerentes com os obtidos por via do estudo dos nanofósseis calcários (CACHÃO 1990) da malacofauda (SILVA 2001) e do conteúdo polínico (DINIZ 1984a).

Tab. 1. Análise polínica das lumachelas de Vale do Freixo, Vale Bouchada, Vale Farpado e do nível arenoso de Vale Bouchada.

Tab. 1. Pollen analysis of the fossiliferous beds of Vale do Freixo, Vale Bouchada, Vale Farpado and the sandy bed of Vale Bouchada.

\begin{tabular}{|c|c|c|c|c|c|c|c|c|}
\hline \multirow[t]{2}{*}{ TAXONES } & \multicolumn{2}{|c|}{$\begin{array}{c}\text { V. FREIXO } \\
\text { Amostra } \quad \text { C12 / } 3\end{array}$} & \multicolumn{2}{|c|}{$\begin{array}{l}\text { V. BOUCH. Aren } \\
\text { Am. C5 / } 2\end{array}$} & \multicolumn{2}{|c|}{$\begin{array}{c}\text { V. BOUCHADA } \\
\text { Am. C } 2 / 2\end{array}$} & \multicolumn{2}{|c|}{$\begin{array}{c}\text { V. FARPADO } \\
\text { J. C / } 3\end{array}$} \\
\hline & g. p. & $\%$ & g. p. & $\%$ & g. p. & $\%$ & g. p. & $\%$ \\
\hline Cathaya & 7 & 6.86 & 5 & 4.76 & 12 & 5.04 & 15 & 2.95 \\
\hline Cedrus & & & & & & & 1 & 0.19 \\
\hline Pinus & 49 & 48.03 & 38 & 36.19 & 145 & 60.92 & 231 & 45.38 \\
\hline Tsuga & & & & & & & 1 & 0.19 \\
\hline Abies & & & & & 1 & 0.42 & 1 & 0.19 \\
\hline Cupressaceae & & & & & & & 5 & 0.98 \\
\hline Sciadopitys & & & & & 1 & 0.42 & & \\
\hline tipo Sequoia & 1 & 0.98 & 4 & 3.80 & 10 & 4.20 & 30 & 5.89 \\
\hline tipo Taxodium & & & & & 6 & 2.50 & 2 & 0.39 \\
\hline Taxodiaceae & & & 2 & 1.90 & 1 & 0.42 & 2 & 0.39 \\
\hline Cyrillaceae / Clethraceae & & & & & & & 5 & 0.98 \\
\hline Myrica & 3 & 2.94 & 7 & 6.66 & 4 & 1.60 & 8 & 1.57 \\
\hline Sapotaceae & 1 & 0.98 & & & & & & \\
\hline Microtropis fallax & & & & & 2 & 0.84 & & \\
\hline Palmae & 1 & 0.98 & 1 & 0.95 & 1 & 0.42 & 2 & 0.39 \\
\hline Parthenocissus & & & & & 2 & 0.84 & 1 & 0.19 \\
\hline Liquidambar & 1 & 0.98 & 1 & 0.95 & 1 & 0.42 & 1 & 0.19 \\
\hline Hamamelidaceae & & & 1 & 0.95 & 1 & 0.42 & & \\
\hline Rhus & 1 & 0.98 & & & 1 & 0.42 & & \\
\hline tipo Castanea & 1 & 0.98 & 1 & 0.95 & 3 & 1.20 & 10 & 1.96 \\
\hline Quercus & 8 & 7.84 & 10 & 9.50 & 19 & 7.98 & 33 & 6.48 \\
\hline Celtis & 1 & 0.98 & & & 2 & 0.84 & & \\
\hline Ostrya & 2 & 1.96 & & & 1 & 0.42 & 1 & 0.19 \\
\hline Ulmus & & & 1 & 0.95 & & & & \\
\hline cf. Carpodiptera & & & & & 1 & 0.42 & & \\
\hline Acer & & & & & 1 & 0.42 & & \\
\hline Alnus & & & 3 & 2.85 & 2 & 0.84 & 3 & 0.58 \\
\hline Salix & 1 & 0.98 & & & & & & \\
\hline Olea & 3 & 2.94 & 6 & 5.71 & 1 & 0.42 & 1 & 0.19 \\
\hline Phillyrea & & & & & & & 5 & 0.98 \\
\hline Oleaceae & & & & & 1 & 0.42 & 10 & 1.96 \\
\hline Rhamnaceae & & & & & & & 4 & 0.78 \\
\hline Myrthaceae & & & & & 1 & 0.42 & & \\
\hline Quercus tipo ilex-coccifera & & & 13 & 12.58 & 1 & 0.42 & 1 & 0.19 \\
\hline Ericaceae & 16 & 15.7 & 3 & 2.85 & 3 & 1.26 & 15 & 2.95 \\
\hline Cistaceae & 1 & 0.98 & & & & & 5 & 0.98 \\
\hline Scrophulariaceae & & & & & 1 & 0.42 & & \\
\hline Plantago & 1 & 0.98 & & & & & & \\
\hline Rumex & & & & & 1 & 0.42 & 1 & 0.19 \\
\hline Rosaceae & & & & & 1 & 0.42 & 1 & 0.19 \\
\hline Poaceae & & & 2 & 1.90 & 2 & 0.84 & 4 & 0.78 \\
\hline Apiaceae & 1 & 0.98 & & & 1 & 0.42 & & \\
\hline Ephedra & 1 & 0.98 & & & & & & \\
\hline Asteraceae tubiflorae & 1 & 0.98 & & & 2 & 0.84 & 4 & 0.78 \\
\hline Asteraceae liguliflorae & 1 & 0.98 & & & & & 3 & 0.58 \\
\hline Amaranthaceae /Chenopodiaceae & & & 3 & 2.85 & 6 & 2.52 & 4 & 0.78 \\
\hline Cyperaceae & & & 4 & 3.80 & & & 2 & 0.39 \\
\hline Total de grãos de pólen & 102 & & 105 & & 238 & & 416 & \\
\hline Sphagnum & & & & & & & 2 & 0.47 \\
\hline Osmunda & & & & & & & 1 & 0.23 \\
\hline Polypodiaceae & & & & & & & 1 & 0.23 \\
\hline Esporos trifidos & 5 & 4.60 & 1 & 0.94 & 4 & 1.65 & 2 & 0.47 \\
\hline $\begin{array}{l}\text { Total de grãos de pólen e de } \\
\text { esporos }\end{array}$ & 107 & & 106 & & 242 & & 422 & \\
\hline
\end{tabular}


Tab. 2. Análise polínica da sondagem P1 de Pombal, níveis 5, 6, 11, 14 e 16

Tab. 2. Pollen analysis of borehole P1 in the Pombal region, levels 5, 6, 11, 14 and 16 .

\begin{tabular}{|c|c|c|c|c|c|c|c|c|c|c|}
\hline \multicolumn{11}{|c|}{ Sondagem P1 } \\
\hline \multirow{3}{*}{ TÁXONES } & \multicolumn{2}{|c|}{ Amostra 5} & \multicolumn{2}{|c|}{ Amostra 6} & \multicolumn{2}{|c|}{ Amostra 11} & \multicolumn{2}{|c|}{ Amostra 14} & \multicolumn{2}{|c|}{ Amostra 16} \\
\hline & Cota & 132.50 & & 132.00 & & 130.00 & Cot & 129.00 & & 128.00 \\
\hline & g. p. & $\%$ & g. p. & $\%$ & g. p. & $\%$ & g. p. & $\%$ & g. p. & $\%$ \\
\hline Cathaya & 7 & 2.99 & 21 & 5.64 & 9 & 2.15 & 6 & 2.08 & 10 & 1.86 \\
\hline Cedrus & & & & & 3 & 0.71 & & & & \\
\hline Pinus & 45 & 12.93 & 84 & 22.58 & 99 & 23.74 & 18 & 6.25 & 100 & 18.62 \\
\hline Tsuga & & & & & 2 & 0.47 & & & 6 & 1.11 \\
\hline Abies & & & & & 6 & 1.43 & & & 2 & 0.37 \\
\hline Cupressaceae & 2 & 0.85 & & & & & 10 & 3.47 & 46 & 8.55 \\
\hline Sciadopitys & 1 & 0.42 & & & 5 & 1.19 & 1 & 0.34 & 8 & 1.48 \\
\hline tipo Sequoia & & & & & & & 5 & 1.73 & 14 & 2.6 \\
\hline tipo Taxodium & & & & & & & 1 & 0.34 & 32 & 5.95 \\
\hline Taxodiaceae & & & 4 & 1.07 & & & & & 6 & 1.11 \\
\hline Cyrillaceae / Clethraceae & & & 4 & 1.07 & 1 & 0.23 & & & 4 & 0.74 \\
\hline Myrica & 25 & 10.68 & 106 & 28.49 & 164 & 39.32 & 12 & 4.16 & 4 & 0.74 \\
\hline Nyssa & 6 & 2.56 & 8 & 2.15 & 30 & 7.19 & & & & \\
\hline Symplocos & & & 8 & 2.15 & 21 & 5.03 & & & & \\
\hline Sapotaceae & & & & & & & 2 & 0.68 & 1 & 0.18 \\
\hline Ficus & & & & & 2 & 0.47 & & & & \\
\hline Engelhardia & & & 2 & 0.53 & 19 & 4.55 & 3 & 1.04 & 9 & 1.67 \\
\hline Palmae & & & & & & & & & 1 & 0.18 \\
\hline Loranthaceae & & & & & 1 & 0.23 & & & & \\
\hline Ilex & & & 2 & 0.53 & 11 & 2.63 & & & 1 & 0.18 \\
\hline Araliaceae & & & & & 1 & 0.23 & & & & \\
\hline Liquidambar & & & & & & & 1 & 0.34 & 1 & 0.18 \\
\hline Hamamelidaceae & & & 1 & 0.26 & 8 & 1.91 & & & 4 & 0.74 \\
\hline Celastraceae & & & & & & & & & 2 & 0.37 \\
\hline tipo Castanea & 1 & 0.42 & & & & & 5 & 1.53 & 4 & 0.74 \\
\hline Quercus & 1 & 0.42 & 11 & 2.95 & 3 & 0.71 & 28 & 9.72 & 14 & 2.60 \\
\hline Corylus & & & & & 1 & 0.23 & 1 & 0.34 & 7 & 1.29 \\
\hline Acer & & & 2 & 0.53 & 3 & 0.71 & 7 & 2.14 & & \\
\hline Ostrya & & & & & & & 1 & 0.34 & 1 & 0.18 \\
\hline Betula & & & & & & & 1 & 0.34 & 2 & 0.37 \\
\hline Alnus & 6 & 2.56 & 4 & 1.07 & 1 & 0.23 & 2 & 0.68 & 5 & 0.93 \\
\hline Fraxinus & 1 & 0.42 & & & & & & & & \\
\hline Tiliaceae & & & 1 & 0.26 & & & & & 1 & 0.18 \\
\hline Populus & 1 & 0.42 & & & & & & & 3 & 0.55 \\
\hline Salix & 1 & 0.42 & & & 3 & 0.71 & 5 & 1.73 & 14 & 2.60 \\
\hline Olea & 3 & 1.28 & & & & & 2 & 0.68 & 9 & 1.67 \\
\hline Phillyrea & 1 & 0.42 & & & & & & & 2 & 0.37 \\
\hline Oleaceae & 3 & 1.28 & 2 & 0.53 & 2 & 0.47 & 3 & 1.04 & 24 & 4.46 \\
\hline Rhamnaceae & & & & & & & 32 & 11.11 & & \\
\hline Myrthus & & & & & & & 5 & 1.73 & & \\
\hline Tamarix & & & & & 1 & 0.23 & & & 3 & 0.55 \\
\hline Quercus tipo ilex coccifera & & & & & & & & & 3 & 0.55 \\
\hline Ericaceae & 119 & 50.85 & 92 & 24.73 & 9 & 2.15 & 24 & 7.36 & 11 & 2.04 \\
\hline Resedaceae & 1 & 0.42 & & & 3 & 0.71 & & & & \\
\hline Helianthemum & & & & & & & & & 2 & 0.37 \\
\hline Cistaceae & 2 & 0.85 & 3 & 0.80 & & & & & 1 & 0.18 \\
\hline Scrophulariaceae & & & & & & & & & 2 & 0.37 \\
\hline Fabaceae & & & & & & & 2 & 0.68 & 4 & 0.74 \\
\hline Mentha & & & & & & & & & 1 & 0.18 \\
\hline Rosaceae & & & & & & & & & 4 & 0.74 \\
\hline Armeria & & & & & & & & & 2 & 0.68 \\
\hline Brassicaceae & 5 & 2.13 & 4 & 1.07 & 8 & 1.91 & & & 8 & 1.48 \\
\hline Caprifoliaceae & & & & & & & 3 & 1.04 & & \\
\hline Convolvulaceae & & & & & 1 & 0.23 & 2 & 0.68 & & \\
\hline Polygonaceae & & & & & & & 10 & 3.47 & & \\
\hline Poaceae & 1 & 0.42 & 1 & 0.26 & & & 3 & 1.04 & 2 & 0.37 \\
\hline Apiaceae & & & 4 & 1.07 & & & 31 & 10.76 & 1 & 0.18 \\
\hline Ephedra & & & 2 & 0.53 & & & 6 & 2.08 & & \\
\hline Asteracae tubiflorae & & & 6 & 1.61 & & & 36 & 12.5 & 5 & 0.93 \\
\hline Asteraceae liguliflorae & & & & & & & & & 2 & 0.37 \\
\hline Asteraceae & 1 & 0.42 & & & & & & & & \\
\hline Amaranthaceae / Chenopodiaceae & & & & & & & 3 & 1.04 & 132 & 24.58 \\
\hline Cyperaceae & 1 & 0.42 & & & & & 15 & 5.20 & 18 & 3.35 \\
\hline Total de grãos de pólen & 234 & & 372 & & 417 & & 326 & & 537 & \\
\hline
\end{tabular}


Tab 2. (continuação)

Tab 2. (continued)

\begin{tabular}{|c|c|c|c|c|c|c|c|c|c|c|}
\hline Sphagnum & 296 & 55.43 & 17 & 4.37 & & & & & & \\
\hline Osmunda & & & & & & & 3850 & 91.05 & 5 & 0.91 \\
\hline Polypodiaceae & & & & & & & 2 & 0.04 & 4 & 0.72 \\
\hline Esporos trífidos & 4 & 0.74 & & & & & 50 & 1.18 & 3 & 0.54 \\
\hline & & & & & & & & & & \\
\hline Total de grãos de pólen e de esporos & 534 & & 389 & & 417 & & 4228 & & 549 & \\
\hline
\end{tabular}

VALE DO FREIXO

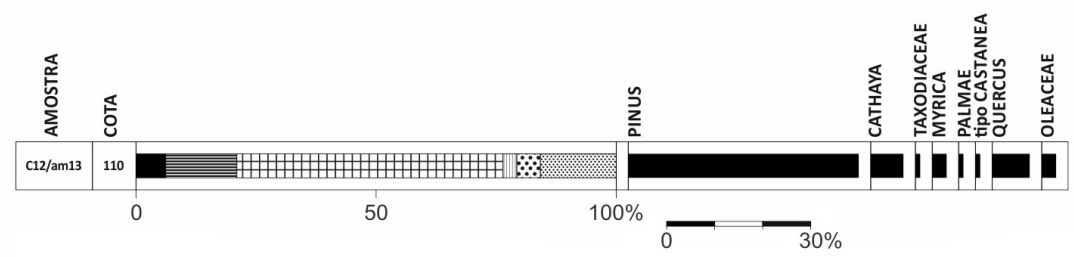

VALE BOUCHADA (nível arenoso)

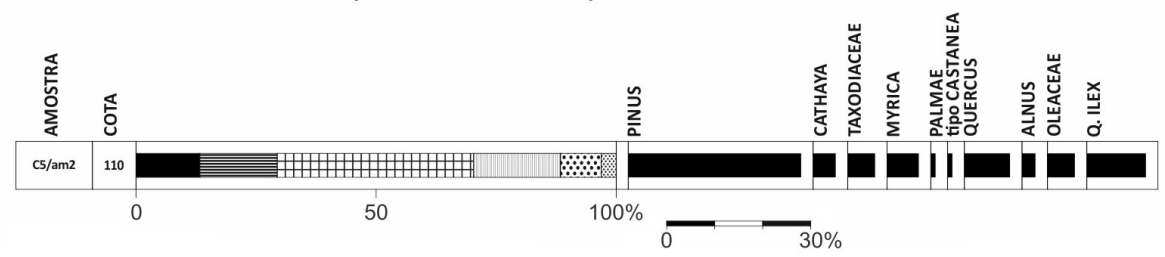

\section{VALE BOUCHADA}
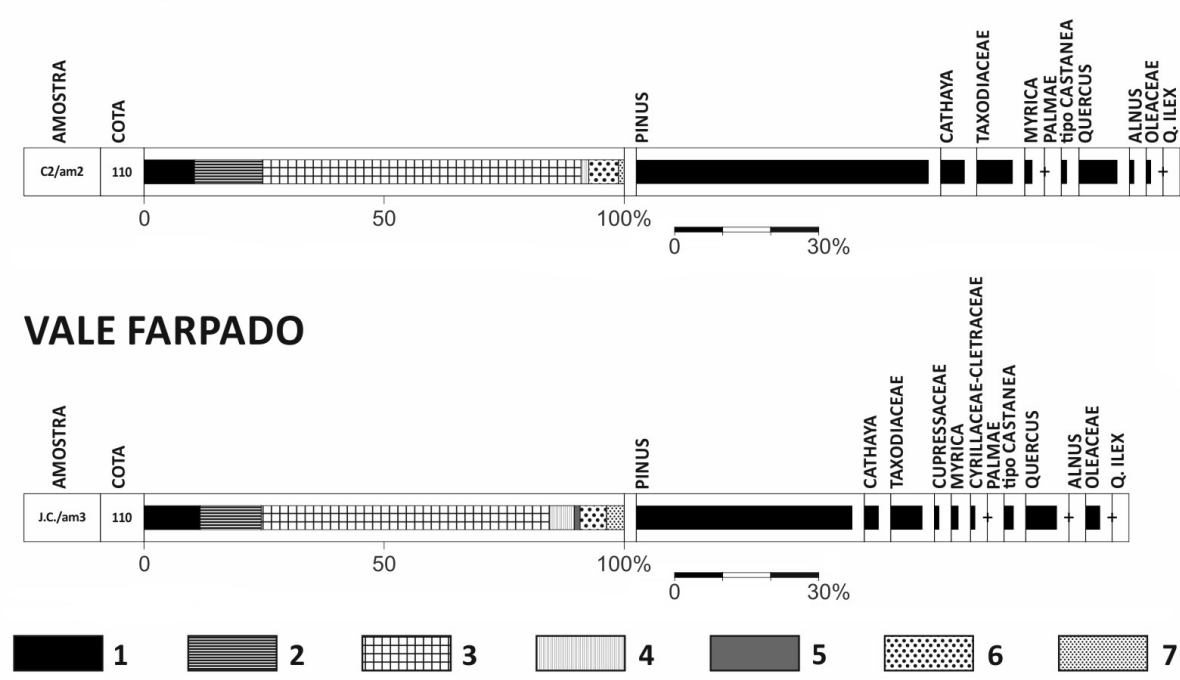

Fig. 2. Vale do Freixo: Espectro polínico simplificado e espectro sintético da lumachela de Vale do Freixo, corte 12, amostra 13 (C12/am13). Vale Bouchada (nível arenoso): Espectro polínico simplificado e espectro sintético do nível arenoso sobreposto à lumachela de Vale Bouchada, C5/am2. Vale Bouchada: Espectro polínico simplificado e espectro sintético da lumachela de Vale Bouchada, C2/am2. Vale Farpado: Espectro polínico simplificado e espectro sintético da lumachela de Vale Farpado, J.C./am3. Legenda dos espectros e diagramas: 1. Táxones de clima quente e húmido (Taxodiaceae, Myrica, Cyrillaceae-Clethraceae, Nyssa, Sapotaceae, Magnolia, Engelhardia, ...); 2. Táxones cujos representantes actuais suportam temperaturas mais baixas mas que apreciam um certo grau de humidade (Liquidambar, Querqus, Acer, Carya, Carpinus, Alnus, ...); 3. Gimnospérmicas (Pinus, Cathaya, Cedrus, ...); 4. Táxones actualmente caracteríscos da flora mediterrânica (Olea, Phillyrea, Quercus tipo ilex-coccifera, ...); 5. Cupressaceae; 6. Herbáceas (Poaceae, Apiaceae, Helianthemun, ...); 7. Ericaceae. As percentagens inferiores a 1\% estão representadas por uma cruz.

Fig. 2. Vale do Freixo: Simplified and synthetic pollen spectrum of the fossiliferous bed of Vale do Freixo, sample C12/13. Vale Bouchada (nível arenoso / sandy beds): Simplified and synthetic pollen spectrum from the sandy bed immediately above the fossiliferous bed of Vale Bouchada, sample C5/2. Vale Bouchada: Simplified and synthetic pollen spectrum of the fossiliferous bed of Vale Bouchada, sample C2/2. Vale Farpado: Simplified and synthetic pollen spectrum of the fossiliferous bed of Vale Farpado, sample J.C./3. Captions of the pollen spectra and diagrams: 1.Trees of subtropical forest (Taxodiaceae, Myrica, Cyrillaceae-Clethraceae, Nyssa, Sapotaceae, Magnolia, Engelhardia, ...); 2. Trees of temperate forest (Liquidambar, Quercus, Acer, Carya, Carpinus, Alnus, ...); 3. Gymnosperms (Pinus, Cathaya Cedrus, ...); 4. Mediterranean trees and shrubs (Olea, Phillyrea, Quercus tipo ilex-coccifera, ...); 5. Cupressaceae; 6. Herbs (Poaceae, Apiaceae, Helianthemun, ...); 7. Ericaceae. Percentages less than $1 \%$ are represented by a cross. 

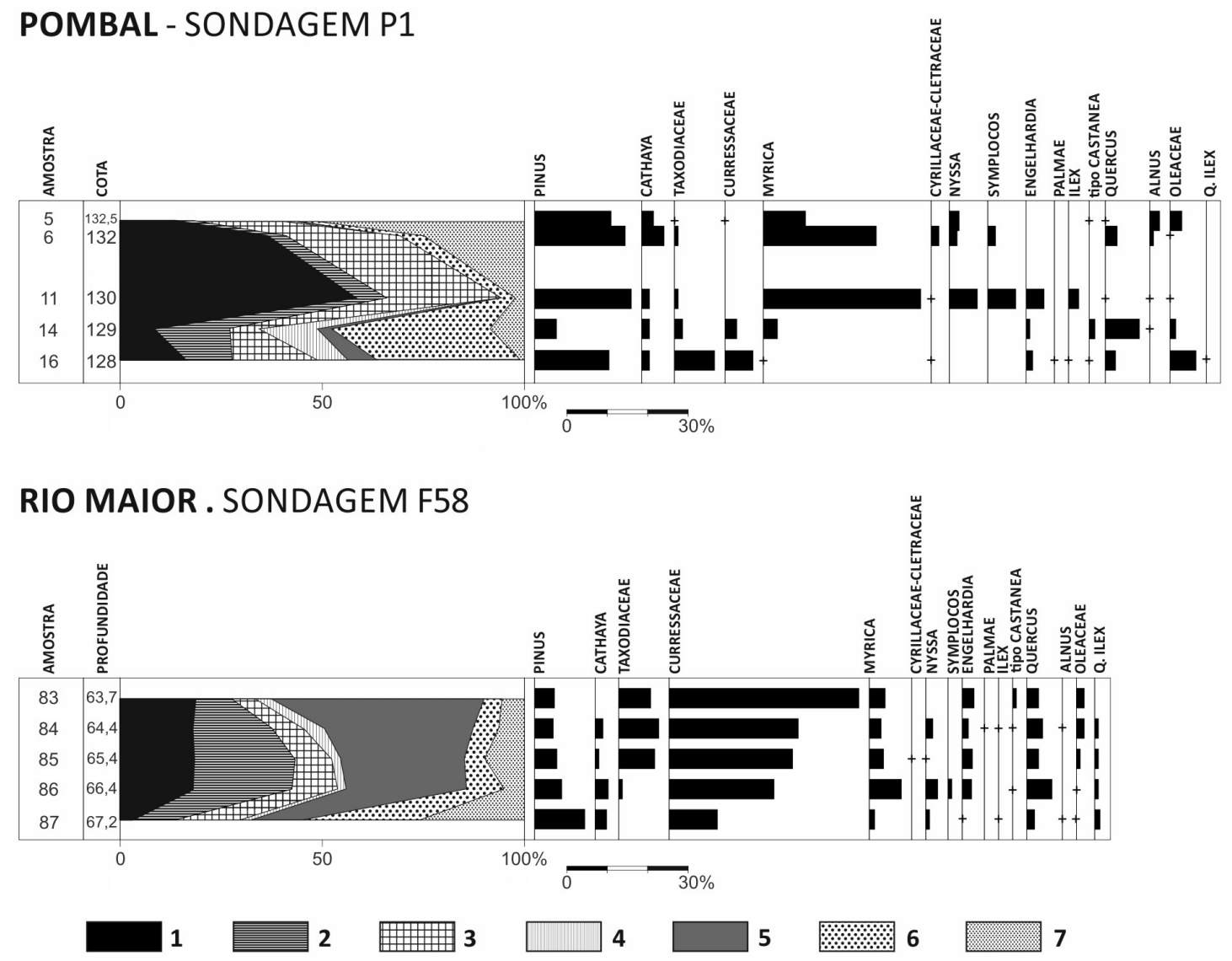

Fig. 3. Pombal - Sondagem P1: Diagrama polínico simplificado e diagrama sintético da sondagem P1 de Pombal, amostras 5, 6, 11, 14 e 16. Rio Maior - Sondagem F58: Diagrama polínico simplificado e diagrama sintético da sondagem F 58 de Rio Maior, conjunto esporo-polínico F, amostras 83 a 87.

Fig. 3. Pombal - Sondagem P1: Simplified and synthetic pollen diagram from Pombal, cored section P1, samples 5, 6, 11, 14 and 16 . Rio Maior - Sondagem F58: Simplified and synthetic pollen diagram from Rio Maior, cored section F 58, palynological zone F, samples 83 to 87.

\subsection{Sondagens de Pombal}

Trinta e seis sondagens implantadas na região de Pombal entre Alto dos Crespos e Vale Coimbra (Fig. 1) atravessaram uma série constituída, da base para o topo, por areias finas amareladas, micáceas da Formação de Carnide, areias finas brancas, siliciosas da Formação de Roussa e argilas com lignitos intercalados da Formação de Barracão (BARBOSA 1983). Segundo este autor (op. cit.) as areias de Roussa testemunham a existência de um cordão litoral de orientação NE-SW entre Pombal e Leiria e as argilas com lignitos ter-se-iam depositado em meio fluvial, num meandro abandonado em plataforma aluvionar.

Das vinte sondagens selecionadas para o estudo palinológico somente os níveis de argila lignitosa sobrejacentes às areias de Roussa são férteis em pólen. A sondagem P1 (cota 156,23 m), é a mais representativa. A microflora, muito diversificada, é caracterizada pela abundância de pólenes de Myrica, Pinus e Ericaceae, acompanhados de Quercus, Alnus, Symplocos, Nyssa e Engelhardia.

O nível 16 é o mais profundo. Quanto aos elementos subtropicais, os grãos de pólen de Taxodium são abundantes, seguidos de Sequoia e em menor grau de Engelhardia. No grupo dos táxones temperados, Quercus é o melhor representado. No grupo dos mediterrânicos Oleaceae perfaz 6,5\%. Quercus ilex é vestigial. Cupressaceae alcança $8 \%$. Amaranthaceae/Chenopodiaceae atingem 24\%. No nível 14 assiste-se à redução de Taxodiaceae. Myrica aumenta até aos 4\% e Engelhardia decresce. Quercus é o elemento mais importante $(10 \%)$, seguido de Acer, tipo Castanea e Salix, variando de 1 a $2 \%$. Corylus, Ostrya, Betula e Alnus são vestigiais. Rhamnaceae atinge $11 \%$, Myrtus e Olea apenas $1 \%$. Cupressaceae regride para 3,5\%. Amaranthaceae/Chenopodiaceae decresce para 5\%. No nível 11 observa-se a expansão de Myrica (40\%). Cyrillaceae/Clethraceae é vestigial. Quercus e Alnus têm percentagens inferiores a $1 \%$, bem como Oleaceae. Ausência de Cupressaceae. Herbáceas e Ericaceae apresentam frequências baixas. No nível 6 Myrica mantém-se importante $(10 \%)$. Cyrillaceae/Clethraceae sobe, Nyssa e Symplocos decrescem. Quercus aumenta até 3\% e Alnus sobe 
timidamente. Oleaceae é vestigial. Finalmente no nível 5 Myrica decresce para 10\%, Nyssa sobe ligeiramente. Quercus e Castanea são vestigiais. Alnus atinge a frequência mais alta $4,5 \%$ e Oleaceae perfaz quase $3 \%$.

Do exposto pode concluir-se que os espectros referentes aos níveis macrofossilíferos são correlacionáveis com os níveis 14 e 16 da sondagem P1 de Pombal, em virtude da boa representação de Taxodiaceae e das percentagens mais elevadas de táxones temperados, relativamente às de táxones subtropicais, o que abona a favor da existência de uma floresta de carácter mesófilo. A partir do nível 11 assiste-se ao desenvolvimento de táxones subtropicais (Myrica, Nyssa, Symplocos e Engelhardia), em detrimento de Taxodiaceae, o que indica a presença de vegetação palustre, sugestiva de uma subida de temperatura.

Estas análises vieram confirmar resultados anteriores (DINIZ 1984a; DINIZ \& CACHÃO 1987) e alargar o inventário paleoflorístico, permitindo um estudo paleoecológico mais rigoroso.

\subsection{Bacia de Rio Maior}

Em Rio Maior, na fachada atlântica centro ibérica, o estudo palinológico de duas sondagens (F58 e F16) permitiu apreender as características de uma flora complexa, constituída por elementos hoje acantonados na Ásia, América do Norte e Macaronésia, lado a lado com outros que povoam actualmente as costas europeias do Atlântico e do Mediterrâneo. Constatou-se o desenvolvimento e posterior declínio do grupo palustre subtropical e o progressivo empobrecimento da floresta esclerófila, em favor de uma vegetação aberta de carácter mais temperado, com alternância entre cobertos vegetais abertos e fechados (DINIZ 1984a, b; DINIZ 2003a).

A reconstituição dos ecossistemas vegetais e da sua evolução, viabilizou o estabelecimento de uma zonação polínica e de correlações palinostratigráficas e climatostratigráficas, com sequências cronologicamente bem calibradas do norte da Europa (ZAGWIJN 1960) e do Mediterrâneao (SUC \& ZAGWIJN 1983); elas advogam a existência de depósitos de idade zancleana e placenciana, tendo sido estabelecido o limite no topo do conjunto esporo-polínico D (DINIZ 1984a). No presente trabalho este limite é redefinido para o topo do conjunto esporo-polínico F. No tocante à evolução climática, as oscilações referentes à temperatura e à humidade são nítidas; foram registados dois arrefecimentos aos 4,5 e 3,5 Ma, assinalados à escala global (SUC et al. 1995b), sendo pertinente sublinhar a emergência de um ritmo térmico sazonal aos 3,5 Ma, com a existência de Invernos amenos (SUC et al. 1995a). Na região de Rio Maior, durante o Pliocénico, as temperaturas anuais e a precipitação eram iguais ou superiores às actuais, respectivamente, mais $4^{\circ} \mathrm{C}$ e mais $400 \mathrm{~mm}$ que actualmente (FAUQUETTE et al. 1999).
A microflora da sondagem P1 é muito similar à de Rio Maior. A parte inferior dos diagramas das sondagens profundas de Rio Maior (conjuntos B a F, Zancleano) é caracterizada pelo domínio de táxones termófilos (Myrica, Cyrillaceae/ Clethraceae, Nyssa, Symplocos e Engelhardia), que por vezes ultrapassam 30 a $50 \%$ do total; no topo do conjunto $\mathrm{F}$ as Taxodiaceae atingem as percentagens mais elevadas de todo o diagrama (9\%), parecendo substituir aqueles táxones termófilos, cujos valores decrescem para 5 a 7\%. Esta alteração qualitativa e quantitativa abona a favor de uma diminuição de temperatura e de humidade que, como foi referido, ocorreu aos 3,5 Ma.

A correlação palinológica da sondagem P1 com o topo do conjunto F de Rio Maior baseia-se nos valores mais elevados dos táxones temperados relativamente aos táxones subtropicais; na presença de Taxodiaceae e nas baixas frequências de táxones termófilos, Nyssa, Symplocos e Engelhardia. Os altos valores de Myrica em certos níveis não contrariam a correlação com o conjunto $\mathrm{F}$, onde este táxon atinge percentagens relevantes nos espectros inferiores. A abundância de pólenes de Cupressaceae no referido conjunto pode estar relacionada com o preenchimento lacustre da bacia evidenciado pela existência de diatomitos na parte superior. É de referir a presença de macrorrestos vegetais de Juniperoxylon juniperoides (KownAs 1951; HUARD 1966), da família das Cupressaceae, tanto nos diatomitos de Rio Maior (PAIS, 1987), como noutras localidades, designadamente em Altos dos Crespos, em Pombal, e Barracão, na região de Leiria (DINIZ 1984a).

As camadas pertencentes ao conjunto $\mathrm{F}$ de Rio Maior situam-se entre a sequência lignitosa/ diatomítica (conjuntos $\mathrm{A}$ a E) e a sequência de diatomitos (conjunto G e H). São constituídas, do topo para a base, por: diatomito lignitoso (amostras 83 e 85), diatomito com intercalações de lignito (amostras 84 e 87), lignito com diatomito (amostra 86 ), de acordo com a figura 3 ; segue-se camada de lignito ( $7 \mathrm{~m}$ de espessura), camada de diatomito lignitoso e, novamente, uma camada de lignito, ambas com cerca de 1,5 m de espessura (DINIZ 1984a).

Uma primeira consequência da atribuição dos espectros polínicos de Vale Farpado, Vale do Freixo, Vale Bouxada e dos níveis da sondagem P1 de Pombal, ao topo do conjunto esporo polínico $F$ seria a correlação dos conjuntos $\mathrm{F}$ e $\mathrm{G}$ a uma fase transgressiva. Esta hipótese é reforçada pela presença, no conjunto $G$ da sondagem $F 16$ de Rio Maior, de quistos de dinoflagelados e pela presença, numa sondagem próxima (AC03) a uma cota comparável, de fósseis de bivalves marinhos, entre os quais Palliolum excisum (BRONN 1831) [= Chlamys excisa (DINIZ 1984a). Uma segunda consequência seria a de datar como Zancleano/Placenciano o topo do conjunto $\mathrm{F}$ em virtude do posicionamento dos níveis fossilíferos de 
Vale do Freixo por via do estudo de nanofósseis calcários (CACHÃO 1990) e da malacofauna (SILVA et al. 2010, et hoc opus).

Por outro lado, o estudo palinostratigráfico e magnetostratigráfico dos cortes de ABUM 1 e ABUM 2 (DINIZ \& MÖRNER 1995), que correspondem ao preenchimento lacustre (diatomitos) da Bacia de Rio Maior até à transição para a sequência detrítica, evidencia o progressivo empobrecimento paleoflorístico (DINIZ 2003b). A polaridade normal observada nas duas secções foi interpretada como respeitante ao evento Gauss e a polaridade inversa registada no topo de ABUM 1, como correspondente ao evento Matuyama. No perfil de ABUM as quatro zonas assinaladas (N-I-N-I) foram consideradas como referentes à Época Gauss inferior, incluindo provavelmente os eventos Kaena (3,11-3,04 Ma) e Mammoth (3,33-3,28 Ma). A inversão Gauss-Matuyama corresponde ao limite entre o Placenciano e o Gelasiano (2,58 Ma) e a inversão Gauss-Gilbert ocorreu aos 3,45-3,5 Ma. ABUM 2 corresponde palinologicamente ao topo do conjunto $F$ e à parte inferior do conjunto $G$ do diagrama de Rio Maior; ABUM 1 pode ser correlacionado com a parte superior do conjunto $\mathrm{H}$. No topo do conjunto $\mathrm{F}$ observa-se o desaparecimento da maioria dos táxones termófilos e em ABUM 1 o grupo subtropical, já deficitário, é superado pelo grupo de elementos temperados. Os últimos níveis registam a degradação da vegetação, persistindo apenas Pinus, Ericaceae, Myrica e Alnus (DINIZ 2003b). Estes estudos vêm corroborar as correlações palinostratigráficas estabelecidas entre os níveis marinhos de Pombal e o conjunto $\mathrm{F}$ de Rio Maior, demonstrando que a sequência palinológica da sondagem de Rio Maior abrange o Zancleano e o Placenciano, como aliás a evolução dos paleoecossistemas já havia demonstrado. Se tivermos em conta a extinção de certos táxones (PostigOMiJARRA et al. 2009), a abundância de Cyrillaceae/ Clethraceae nos conjuntos B, D e base de F da sondagem F58 de Rio Maior abona a favor da idade zancleana destes depósitos pois, segundo estes autores, este táxon extingue-se no final do Zancleano.

A comparação entre diagramas de sequências importantes faz-se segundo uma metodologia que utiliza sempre o mesmo critério para o cálculo das percentagens e socorre-se dos mesmos grupos bioclimáticos ou seus equivalentes, na interpretação paleoecológica e paleoclimática da vegetação, por forma a garantir uma comparação fiável. Este critério foi amplamente utilizado nos trabalhos de síntese referentes ao transepto latitudinal da fachada atlântica (SUC et al. 1995b), clima e biomas do mediterrânico ocidental (FAUQUETTE et al. 1999) modificações da vegetação neogénica na Europa ocidental e no Mediterrâneo ocidental (SuC et al. 1999) em que os dados do estudo palinológico de Rio Maior foram integrados.
Os recentes estudos palinológicos em várias jazidas da orla ocidental e da sondagem F 98 de Rio Maior (BARÓN et al. 2010; VIEIRA et al. 2006; VIEIRA 2009; VIEIRA et al. 2011) constituem documentos importantes para o conhecimento da vegetação do Cenozóico superior da Península Ibérica. A identificação de novos táxones veio enriquecer o cortejo paleoflorístico e fornecer novos elementos paleoecológicos. Para compararmos estes resultados com as sequências referidas em Rio Maior e noutras localidades importantes, seria pertinente que os diagramas fossem configurados segundo os critérios já enunciados, designadamente no que respeita a Vale do Freixo, Barracão e sondagem F98 de Rio Maior.

Com base no trabalho de Vieira (2009) não é claro, na ausência de um diagrama, em que se fundamentou a correlação palinostratigráfica apresentada dos níveis fossilíferos da sequência de Vale do Freixo; no tocante a Barracão, não é evidente se existe lacuna entre as duas amostras da base e a restante sequência. Relativamente ao diagrama da sondagem F 98, importaria saber quais os fundamentos palinostratigráficos ou outros para a sua atribuição unicamente ao Placenciano quando o grupo dos táxones mega-mesotérmicos apresenta várias oscilações, atingindo valores elevados (associação II e V), e é referida degradação climática na associação IX.

\section{NANOFÓSSEIS CALCÁRIOS}

\subsection{Biostratigrafia}

Estudos subsequentes incidindo na componente em nanofósseis calcários (CACHÃo 1989, 1990, 1995) das unidades fossilíferas da base da Formação de Carnide que afloram interruptamente desde esta localidade (Oeste de Pombal) até Vale de Paredes (Marinha Grande) e Lagoa de Óbidos (Caldas da Rainha) permitiram não só aferir o seu posicionamento biostratigráfico à biozona $\mathrm{CN} 12 \mathrm{a}$ de Okada \& Bukry (1980). Esta biozona, grosso modo, corresponde ao andar Placenciano, com um intervalo biocronológico entre 3,61 (LAD de Sphenolithus spp.) e 2,76 Ma (LAD de Discoaster tamalis ) de acordo com Backman et al. (2012).

\subsection{Interpretação paleoambiental}

As associações de nanofósseis calcários encontradas podem ser caracterizadas como pobres (nenhum estudo quantitativo absoluto foi realizado, mas apenas observações semi-quantitativas), dominadas por placólitos e helicólitos, com ausência quase completa de formas típicas de domínios oceânicos (e.g., asterólitos). Este facto corroborou o carácter costeiro das bio e litofácies das unidades fossilíferas.

Apenas uma questão ficava por responder: qual a razão de Coccolithus pelagicus s.l. aparecer em tão grande quantidade, por vezes a única forma encontrada nas amostras. Por um lado a sua relativa robustez poderia dar uma explicação, conside- 
rando que as demais formas teriam sofrido dissolução diagenética. Contudo, a qualidade de preservação e a presença de uma componente argilosa significativa, derivada da remobilização da fracção fina da Formação de Dagorda que extruiu no interior nos vales tifónicos (CACHÃO 1989) não argumentava a favor de uma explicação estritamente tafonómica, nem diagenética, nem de carácter biostratonómico, por remobilização de níveis miocénicos marinhos das vizinhanças. Ora a unidade miocénica da região, a Formação de Amor, é de fácies continental e não é fácil ou mesmo possível argumentar que apenas placólitos de uma só espécie de nanofósseis calcários pudessem ser remobilizados de unidades miocénicas mais a sul da Bacia do Tejo-Sado para esta região sem que, com eles, viessem outros taxa mais antigos, algo que nunca foi observado.

Desde os trabalhos pioneiros de McIntyre \& Bé (1967) C. pelagicus foi conotado com (paleo) ambientes de fácies oceânica e águas subpolares. A primeira característica entrava em contradição directa com as restantes evidências faciológicas e paleobiogeográficas da Formação de Carnide, costeira e associada a paleoarribas litorais geradas pelos vales tifónicos da região de Caldas da Rainha. A segunda também não era corroborada pelas características paleoclimáticas fornecidas pelos elementos palinológicos e por todos os outros grupos de macro e microfósseis incluindo os nanofósseis calcários, nos quais foi possível encontrar uma associação de Discoasterídeos, tipicamente associados a águas quentes (CACHÃO 1995).

Esta questão só foi possível de ser esclarecida quando estudos feitos em amostras atuais e da coluna da água, realizados na região da plataforma continental portuguesa vieram comprovar a ocorrência de $C$. pelagicus s.l. em contextos neríticos de massas de água temperadas, associada a frentes com correntes ascendentes por afloramento costeiro (CACHÃO 1995; CACHÃO \& MOITA 2000), espécie esta atualmente considerada como uma subespécie distinta, Coccolithus pelagicus subspecies braarudii, por critérios morfométricos (PARENTE et al. 2004, NARCISO et al. 2006) e genéticos (GEISEN et al. 2002).

De acordo com estes dados pode-se atribuir a abundante presença de Coccolithus pelagicus braarudii no Pliocénico marinho de Caldas da Rainha Pombal a um paleoambiente de características neríticas, no âmbito do qual existiriam condições para o desenvolvimento de afloramento costeiro persistente (upwelling) e, deste modo, condições de significativa produtividade marinha no decurso do Placenciano, superiores às que ocorrem atualmente ao largo da nossa costa, muito provavelmente semelhantes às descritas por Giraudeau \& Rogers (1994) para o offshore de Benguela.

\section{MALACOFAUNA PLIOCÉNICA: PONTO DA SITUAÇÃ ${ }^{1}$}

\subsection{Enquadramento histórico e problemáti- cas de estudo}

Uma característica notável dos sedimentos pliocénicos de fácies marinha da região de Carnide (Pombal) é o seu rico conteúdo macrofossilífero. Foi há 65 anos que Teixeira \& Zbyszewsky (1951) reportaram pela primeira vez a ocorrência de fósseis de moluscos gastrópodes e bivalves dessas camadas. Os referidos autores mencionam vários locais onde os níveis fossilíferos da base da sequência pliocénica - posicionada nesta região à cota aproximada de $110 \mathrm{~m}$ - aflora: Carnide de Cima, Igreja de Carnide, Vale Bouchada, Vale Farpado e Vale de Cabra (Fig. 1).

Num enquadramento geográfico mais amplo, a ocorrência de associações macrofossilíferas pliocénicas na região Oeste central de Portugal, a norte do Tejo, nas imediações de Caldas da Rainha (e.g., Choffat 1889; Dollfus \& CotTer 1909) e da Marinha Grande (e.g., Cox 1936, 1941; MORAIS 1936, 1941) era já conhecida desde finais do séc. XIX, sendo as da região de Pombal as que mais recentemente foram reportadas e estudadas, já na década de 1950.

Em Zbyszewsky (1959) é feita uma revisão do conhecimento das associações de moluscos pliocénicos da região de Caldas da Rainha - Marinha Grande e, em particular, de Pombal. O tema volta a ser abordado em Brébion (1971, 1974). Após os trabalhos de Philippe Brébion o estudo das associações de fósseis de moluscos pliocénicos de Portugal cai no esquecimento, só voltando a ser retomado no início da década de 1990 com os trabalhos de Silva (1990, 1991, 1992, etc.), impulsionados pela descoberta por Filomena Diniz e Liliana Póvoas, em 1980, do afloramento de Vale do Freixo, exposto no decurso de trabalhos de exploração de um barreiro (explorando os Argilitos de Amor), a apenas $450 \mathrm{~m}$ a SW da Igreja de Carnide (Vale do

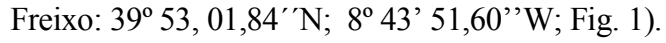

Desde os primeiros trabalhos sobre este tema, para além dos aspectos taxonómicos de base, fundamentais em qualquer trabalho paleontológico (vide "Taxonomia da malacofauna pliocénica portuguesa: ponto da situação", abaixo), a questão do posicionamento cronostratigráfico dos níveis fossilíferos pliocénicos marinhos foi uma preocupação central dos paleontólogos que sobre eles se debruçaram. As conclusões a que, ao longo do tempo, os diversos investigadores chegaram estavam longe de ser consensuais, sobretudo devido a discrepâncias nomenclaturais resultantes da natural evolução do entendimento das unidades cronostratigráficas

${ }^{1}$ Neste capítulo sobre a malacofauna de Vale do Freixo (por CMS) usaram-se os nomes das unidades cronostratigráficas preconizados em Silva (2010) para uso nas aulas de Paleontologia do Departamento de Geologia da FCUL, mais generalizada e tradicionalmente usados na literatura geológica e paleontológica nacional, uma vez que o autor não se revê nos nomes empregues na versão portuguesa da "Tabela Cronoestratigráfica Internacional" [sic] de 2013 da iniciativa da Comissão Internacional de Estratigrafia (v 2013/01) de Sá et al. (2013). 
envolvidas. Assim, Choffat (1889) posicionou-os no "Pliocénico superior" o que, em termos actuais corresponderia, grosso modo, ao Plistocénico, Calabriano. Teixeira \& Zbyszewsky (1951) e Zbyszewsky (1959), atribuíram-nos ao "Pliocène inférieur marin au Plaisancien-Astien" (TEIXEIRA \& ZBYSZEWSKY 1951: 301), correspondendo presentemente ao Placenciano (Pliocénico) - Gelasiano (Plistocénico). Mais tarde, Brébion (1971) atribui a malacofauna em estudo ao Pliocénico superior, equivalendo actualmente à fatia estratigráfica Placenciano (Pliocénico) - Gelasiano (Plistocénico). O posicionamento destes níveis seria posteriormente precisado lançando mão ao estudo de nanofósseis calcários (Carla Müller in litteris, DINIZ 1984a; CACHÃO 1989, 1990), suplementados por novas abordagens da malacofauna (SILVA 1993 e, sobretudo, SILVA 2001 e Silva et al. 2010). Também Vieira (2009), com base em palinomorfos, discute o posicionamento cronostratigráfico destas camadas fossilíferas marinhas. Os resultados destes estudos, actualizados de acordo com a recente revisão da cronostratigrafia Neogénica de Gradstein et al. (2012) e da biozonação dos nanofósseis calcários de Backman et al. (2012), com tónica especial na interpretação do significado da associação de moluscos, serão apresentados e discutidos abaixo, em "Posicionamento cronostratigráfico e geocronológico".

Uma vez o posicionamento cronostratigráfico resolvido, outros aspectos do estudo da malacofauna pliocénica marinha da região centro-oeste portuguesa se abriam: continuação da revisão taxonómica, interpretação paleoambiental, caracterização paleoecológica da associação fossilífera e paleobiogeografia dos moluscos pliocénicos, esta última intimamente ligada ao seu significado ecostratigráfico.

Cox (1936: 49), debruçando-se sobre a região da Marinha Grande, avança as primeiras considerações de ordem paleobiogeográfica sobre estas associações de moluscos pliocénicos, afirmando: "Althoug the fauna now described has much affinity with that of contemporaneous Mediterranean deposits (...). This fauna (...) has a distinctive character of its one (...)." Mais tarde, Brébion (1971: 132) retoma a questão afirmando que: "Jusqui' ici l'on avait considéré la faune pliocène portugaise dans son ensemble comme méditeranéene. (...) En fait le caractère méditerranéen de la faune, s'il est indiscutable, est moins marqué qu'on ne le pensait." Só mais tarde Silva (2001) retomaria este tema aprofundadamente, beneficiando dos resultados dos trabalhos de Raffi \& Monegatti (1993) e Monegatti \& Raffi (2001) sobre a ecostratigrafia e a paleobiogeografia dos moluscos pliocénicos mediterrânicos. Estes temas serão desenvolvidos abaixo, em "Paleoecologia, Ecostratigrafia e Biogeografia".

Neste capítulo é apresentada síntese e actualização, o ponto da situação, do significado cronostratigráfico, paleoecológico e paleobiogeográfico das associações de moluscos pliocénicos da região centro-oeste portuguesa, em particular de Pombal.

\subsection{Posicionamento cronostratigráfico geocronológico}

Em jeito de enquadramento, do ponto de vista litostratigráfico, formacional, os níveis macrofossilíferos marinhos da base da sequência pliocénica aflorantes na região de Carnide correspondem à base da Formação Arenito Carnide de Cachão (1989), equivalente às "Areias de Carnide" de Barbosa (1983) e à Formação de Carnide em, e.g., Pais et al. (2013), assentando localmente em discorformidade erosiva (CACHÃO 1989) sobre os argilitos da Formação de Amor de idade miocénica (segundo ZBYSZEWSKI \& FERREIRA 1967 e ANTUNES \& MEIN 1981). O conjunto das unidades que no sector SW da Bacia do Mondego, na região de Pombal, incluem a Formação de Carnide, constituindo uma sequência limitada por descontinuidade regional, são englobados por Cunha (1992) na sua unidade alostratigráfica SLD13. Os níveis macrofossilíferos marinhos aqui discutidos inserem-se, portanto, na base da unidade SLD13, constituindo localmente, de modo descontínuo, o início da Formação de Carnide. A relação entre a unidade SLD13, a Formação de Carnide e as restantes unidades cenozóicas da região está ilustrada no "Esquema estratigráfico para o Cenozóico da Bacia do Douro (...) e Bacia do Mondego" apresentado em Cunha et al. (2009: tabela 1), em Pais et al. (2010: tabela 1) e em Pais et al. (2012: fig. 9, em que, seguramente por lapso gráfico, a base da Formação de Carnide abarca o topo da SLD12), bem como em Pais et al. (2013: fig. 3, em que, seguramente por lapso gráfico, não é mostrada a relação lateral entre as formações de - de baixo para cima - Carnide, Roussa e Barracão no sector SW da Bacia do Mondego). De notar que, em alguns trabalhos, a discussão dos dados paleoclimáticos, nomeadamente da temperatura das águas superficiais oceânicas, resultantes da análise da malacofauna dos níveis fossíliferos basais de Vale do Freixo, base da Formação de Carnide (e.g., SILVA, 2001; Silva et al. 2010), é apresentada no seio da caracterização da Formação de Santa Quitéria, respeitante ao sector NE da Bacia do Mondego (vide, e.g., PAIS et al. 2012: 30 e PAIS et al. 2013: 475). Complementarmente, veja-se o enquadramento litostratigráfico e a caracterização da sequência estratigráfica da Formação de Carnide em Ramos (2008).

Segundo Carla Müller (in litteris, DINIZ 1984a), com base em nanofósseis calcários, os níveis macrofossilíferos marinhos da base da sequência pliocénica em Vale Farpado (região de Carnide, Fig. 1) corresponderiam ao intervalo biozonal NN16-NN18 de Martini (1971), ou seja, à fatia cronostratigráfica abarcando actualmente desde o topo do Zancleano (Pliocénico inferior) até 
quase ao topo do Gelasiano (Plistocénico). Mais tarde, Cachão $(1989,1990)$, com base na identificação de discoasterídeos (grupo que Carla Müller não havia referido) provenientes dos níveis fossilíferos da base da secção de Vale do Freixo (Fig. 1), precisou este posicionamento, limitando-o a parte da biozona NN16 de Martini (1971), correspondente à biozona Discoaster tamalis, CN12a de Okada \& Bukry (1980), ou seja, Pliocénico, topo do Zancleano a Placenciano (Fig. 4). Segundo Cachão (1990), com base na notória ausência de Sphenolithus spp. (cujo LAD se posiciona pouco acima da base da biozona CN12a, i.e., 3,70 Ma, geocronolo- gia actualizada segundo GRADSTEIN et al., 2012: 1110, calibrada para o Mediterrâneo) seria ainda possível limitar um pouco mais o intervalo representado para 3,70 a $2,8 \mathrm{Ma}$ (LAD D. tamalis segundo geocronologia de GRADSTEIN et al. 2012: 1110). De salientar que, de acordo com Backman et al. (2012: 236) a cronologia dos eventos LAD de Sphenolithus e de D. tamalis é ligeiramente distinta da apresentada em Gradstein et al. (2012). Assim, para Backman et al. (2012: 236) o LAD de Sphenolithus spp. ocorre a 3,61 Ma e o LAD de $D$. tamalis a 2,76 Ma (Fig. 4).

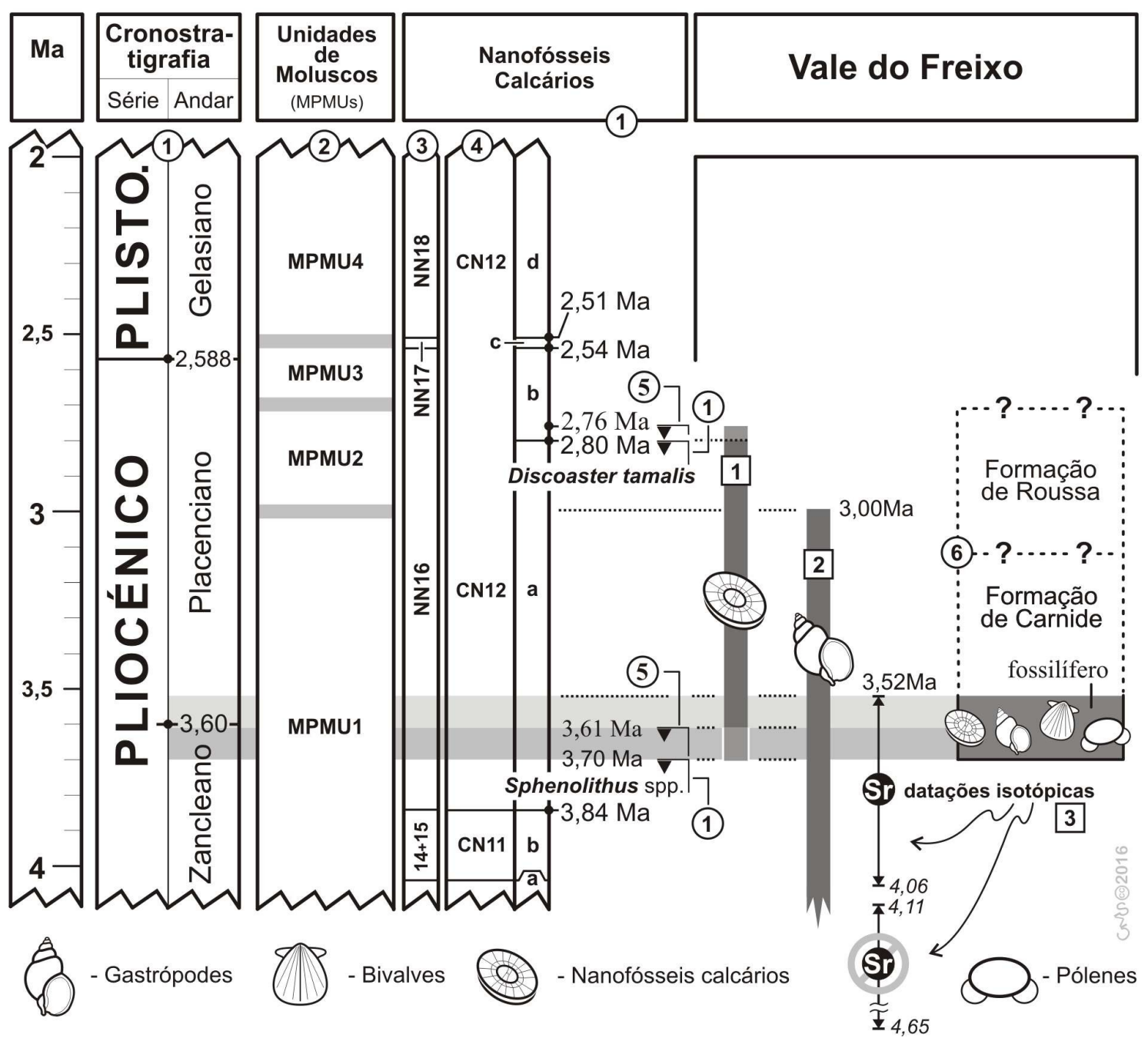

Fig. 4. Posicionamento cronostratigráfico dos níveis fossilíferos marinhos pliocénicos da base da sequência de Vale do Freixo (Carnide, Pombal, Portugal centro-Oeste). Baseado em: (1) - Gradstein et al. (2012: 1110), (2) - Monegatti \& Raffi (2001, 2007), (3) Martini (1971), (4) - Okada \& Burky (1980), (5) - Backman et al. (2012: 236), (6) - Cachão (1989), [1] - Posicionamento estratigráfico com base em nanofósseis calcários (Cachão 1990) e [2] moluscos gastrópodes (SILVA 2001, SILVA et al. 2010); [3] Datações isotópicas (SILVA et al. 2010).

Fig. 4. Chronostratigraphic position of the Pliocene marine basal fossiliferous beds of the Vale do Freixo sequence (Carnide, Pombal, Central West Portugal). Based on: (1) - Gradstein et al. (2012: 1110), (2) - Monegatti \& Raffi (2001, 2007), (3) - Martini (1971), (4) Okada \& Burky (1980), (5) - Backman et al. (2012: 236), (6) - Cachão (1989), [1] - Chronostratigraphic position based on calcareous nannofossils (Cachão 1990) and [2] gastropod molluscs (SILVA 2001, SILVA et al. 2010); [3] Strontium isotope dating (SILVA et al. 2010). 
Vieira (2009), no seu estudo dos palinomorfos da sequência basal marinha de Vale do Freixo, identifica - entre outros - a presença de quistos do dinoflagelado goniaulacóide Operculodinium tegillatum o qual, segundo Louwye et al. (2004), teve no Atlântico Norte uma distribuição temporal entre os 5,0 e os 3,5 Ma, desaparecendo próximo do limite entre as biozonas de nanofósseis calcários NN15 e NN16 de Martini (1971). Vieira (2009) refere que a fatia cronostratigráfica abarcada por $O$. tegillatum corresponde a quase todo o Zancleano e à base do Placenciano, o que se enquadraria bem com os dados obtidos por Cachão (1990) com base nos nanofósseis calcários e por Silva (2001) com base nos moluscos marinhos e nos dados isotópicos de ${ }^{87} \mathrm{Sr} /{ }^{86} \mathrm{Sr}$. De facto, tomando a distribuição cronológica atribuída a $O$. tegillatum, i.e., 5,0 a 3,5 Ma, assim é. Contudo, da actualização da cronologia dos esquemas biozonais de nanofósseis calcários para o Neogénico (BACKMAN et al. 2012; GRADSTEIN et al. 2012) resulta uma discrepância entre a cronologia do desaparecimento de $O$. tegillatum e a do evento biostratigráfico de nanofósseis calcários ao qual, segundo Louwye et al. (2004), tal como referido em Vieira (2009), ele se aproximaria: o limite NN15-NN16. Actualmente, esse limite biozonal (coincidente com o limite CN11b-CN12a de OKADA \& BUKRY 1980, fide BACKMAN et al. 2012), marcado pelo desaparecimento de Reticulofenestra pseudoumbilicus, está posicionado nos 3,82 Ma (BACKMAN et al. 2012) ou nos $3,84 \mathrm{Ma}$ (GRADSTEIN et al. 2012), ou seja, ainda no seio do Zancleano (vide Fig. 4).

Segundo Silva (2001) e Silva et al. (2010), a associação de fósseis de moluscos pliocénicos presente em Vale do Freixo é correlacionável com a MPMU1 (Mediterranean Pliocene Molluscan Unit 1) de Monegatti \& Raffi $(2001,2007)$ (vide "Paleoecologia, Ecostratigrafia e Biogeografia", abaixo). A expressão cronostratigráfica desta MPMU1 mediterrânica é Zancleano-Placenciano médio. Do ponto de vista geocronológico, esta MPMU1 corresponde à fatia temporal 5,33-3,0 Ma (Fig. 4). Ou seja, se intersectarmos o posicionamento obtido com base nos nanofósseis calcários com o resultante dos moluscos, para os níveis fossilíferos da base da sequência pliocénica de Vale do Freixo, obteremos um posicionamento Zancleano superior a Placenciano médio (entre os 3,70 Ma e os 3,0 Ma, geocronologia actualizada segundo GRADSTEIN et al., 2012: 1110). Se conjugarmos o que atrás foi dito com os dados da datação isotópica de estrôncio de pectinídios dos níveis fossilíferos da base da Formação de Carnide em Vale do Freixo (SILVA et al. 2010), então - geocronologicamente - resultará uma idade entre 3,70 a 3,52 Ma (topo do Zancleano a Placenciano inferior). Segundo a geocronologia do LAD de Sphenolithus spp. preconizada por Backman et al. (2012: 236), a datação obtida seria ainda mais constrita: 3,61 a 3,52 Ma.
A coluna litostratigráfica da sequência basal fossilífera da Formação de Carnide em Vale do Freixo pode ser encontrada em Gili et al. (1995), em Nolf \& Silva (1997) ou em Silva et al. (2010).

\subsection{Paleoecologia, Ecostratigrafia e Biogeo- grafia}

De um ponto de vista paleoecológico, paleoambiental, a associação de fósseis de moluscos presente nas camadas fossilíferas de Vale do Freixo indica que, durante o Placenciano ante 3,0 $\mathrm{Ma}$, na região correspondente à actual Carnide existia um ambiente marinho de plataforma interna, de pequena profundidade, infralitoral, com uma profundidade inferior a cerca de $24 \mathrm{~m}$, próximo da costa de então e algo protegido da influência directa do oceano (SILVA 1991, 2001). As condições de salinidade seriam marinhas típicas (circa 35\%o) e o substrato arenoso fino a médio (ibidem). Nolf \& Silva (1997) com base em otólitos de peixes ósseos, tendo em conta que os peixes são organismos pelágicos, chegam a conclusões compatíveis com as obtidas com base nos moluscos bentónicos. Carvalho $(1961,1971)$ com base no estudo dos briozoários chega a conclusões similares no tocante à salinidade, profundidade e temperatura das águas superficiais pliocénicas à latitude de Caldas da Rainha - Marinha Grande - Pombal.

Relativamente à temperatura das águas superficiais oceânicas, segundo Silva (2001) e Silva et al. (2010) com base nos moluscos, esta seria subtropical, similar à actualmente registada nas costas da África Ocidental à latitude do Cabo Branco (Cap Blanc, Mauritânia, $21^{\circ} \mathrm{N}$ ), ou seja: temperaturas médias mensais (TMM) nunca inferiores a $19^{\circ} \mathrm{C}$, com TMM máxima de $23,5^{\circ} \mathrm{C}$ em Setembro e mínima de $19^{\circ} \mathrm{C}$ em Janeiro-Março. Actualmente, na costa portuguesa à latitude de Vale do Freixo, a temperatura média TMM mínima das águas superficiais atlânticas é de $14^{\circ} \mathrm{C}$, de Fevereiro a Março, enquanto a máxima é de $19^{\circ} \mathrm{C}$, entre Junho e Agosto. Durante o Pliocénico ante 3,0 Ma, não apenas a temperatura das águas superficiais oceânicas costeiras seria mais elevada como também o período estival de "águas quentes" seria mais longo. Além disso, Silva et al. (2006) com base na presença de Patella pellucida Linnaeus, 1758 na associação fossilífera de Vale do Freixo concluíram que, durante o Placenciano inferior, algas laminárias fariam parte do ecossistema marinho infralitoral e que, por isso, existiriam já na costa ocidental ibérica condições de elevada produtividade associada a afloramento costeiro, a upwelling.

No que à paleobiogeografia concerne, Silva (2001), Silva \& Landau (2007) e Silva et al. (2010) fundamentam as reservas apresentadas por Cox (1936) e Brébion (1971) quanto a uma identidade total das faunas pliocénicas oeste ibéricas - à latitude $39-40^{\circ} \mathrm{N}-$ com as mediterrânicas. Efectiva- 
mente, há traços em comum, bastantes, mas o certo é que as faunas centro-oeste ibéricas, durante o Pliocénico, pertenciam já a uma província biogeográfica distinta das do Mediterrâneo.

Com base na distribuição das espécies de gastrópodes termófilos pliocénicos das associações do SW ibérico da Bacia do Mondego (Atlântico), do Guadalquivir (SW de Espanha, Atlântico) e da Bacia de Estepona (S de Espanha, Mediterrâneo), todas elas correspondentes ou correlacionáveis com a MPMU1 mediterrânica, e no padrão de quebra no número dessas espécies termófilas desde o Mediterrânico Ocidental até ao Atlântico à latitude da Bacia do Mondego, quer no Pliocénico, quer na actualidade, Silva (2001) conclui que - apesar da acentuada quebra no número de espécies termófilas do Pliocénico para a actualidade (83-85\%) -, o padrão biogeográfico (Fig. 5) e o posicionamento das fronteiras entre as províncias biogeográficas não sofreram alterações significativas face ao que se observa actualmente (Fig. 6). Silva \& Landau (2007), uma vez mais com base nos gastrópodes, reforçam esta interpretação e Monegatti \& Raffi (2007), com base nos bivalves, chegam a conclusões similares.

De um ponto de vista ecostratigráfico, o conteúdo fossilífero de moluscos pliocénicos marinhos da Bacia do Mondego, com base na presença de representantes de táxones termófilos de gastrópodes como Ficus (1 sp.), presença moderada de Conus (2 spp.), de Terebridae (2 spp.), etc. e na ausência de Strombus e de bivalves Veneridae de concha espessa (vide critérios de RAFFI \& MONEGATTI, 1993 e MONEGATTI \& RAFFI, 2001), em conjugação com uma idade isotópica anterior aos 3,0 Ma (vide "Posicionamento cronostratigráfico e geocronológico", acima), corresponde a uma associação correlacionável com a MPMU1 tropical mediterrânica, mas representando a uma unidade biogeográfica distinta, mais setentrional, com um sinal já não tropical (típico das associações MPMU1 mediterrânicas) e sim subtropical (ausência de Strombus e de Veneridae de concha espessa, baixa diversidade de Conus e Terebridae, etc.). De notar que, sendo as MPMUs de Raffi \& Monegatti (1993) e Monegatti \& Raffi (2001) unidades faunísticas, ecostratigráficas, elas apenas são válidas no seio da unidade paleobiogeográfica para a qual foram definidas, i.e., para a região correspondente à Província Pliocénica Mediterrânico-Oeste Africana (Fig. 6). Assim, a associação da Bacia do Mondego (que corresponde a uma província pliocénica distinta, a FrancoIbérica, Fig. 6) não se insere na MPMU1, sendo apenas correlacionável com ela (vide SILVA \& LANDAU, 2007 e MONEGATTI \& RAFFI, 2007).

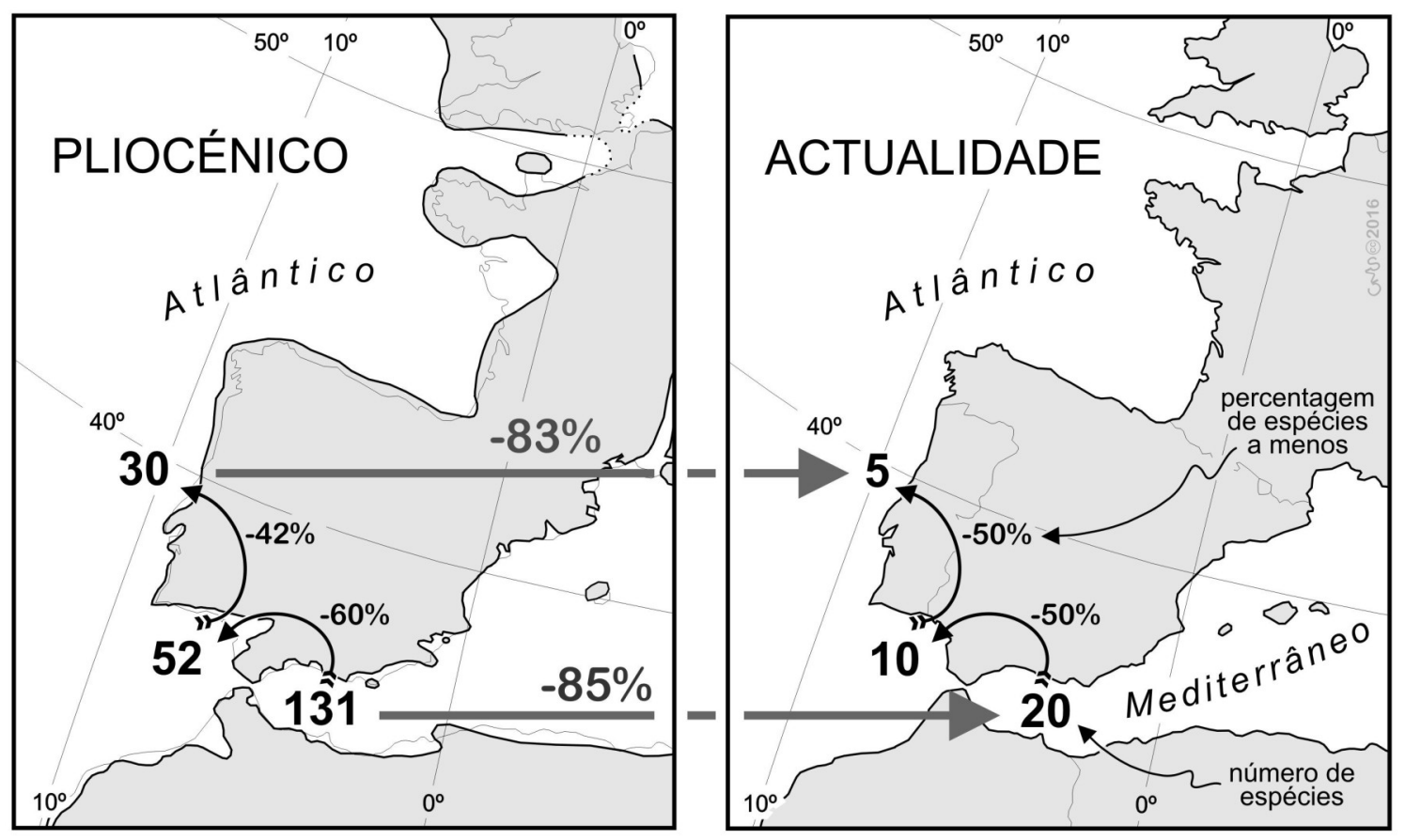

Fig. 5. Análise do padrão de quebra no número de espécies termófilas de gastrópodes das famílias Xenophoridae, Strombidae, Cypraeidae, Ovulidae, Ranellidae, Muricidae, Marginellidae, Terebridae, Architectonicidae, Conidae, Ficidae, etc., desde o Mediterrânico Ocidental até ao Atlântico à latitude da Bacia do Mondego, quer no Pliocénico (de E para W, do Mediterrâneo para o Atlântico: Bacias de Estepona, Guadalquivir e Mondego, vide Fig. 6), quer na actualidade. Adaptado de Silva (2001).

Fig. 5. Analysis of the faunal break pattern in the number of thermophilic species of gastropods of the families Xenophoridae, Strombidae, Cypraeidae, Ovulidae, Ranellidae, Muricidae, Marginellidae, Terebridae, Architectonicidae, Conidae, Ficidae, etc., from the Western Mediterranean into the Eastern Atlantic along the Iberian coast until the latitude of the Mondego Basin. Left: Pliocene (from E to W, from the western Mediterranean into the Atlantic: Estepona Basin, Guadalquivir Basin and Mondego Basin, see Fig. 6); Right: Present day. Adapted from Silva (2001). 


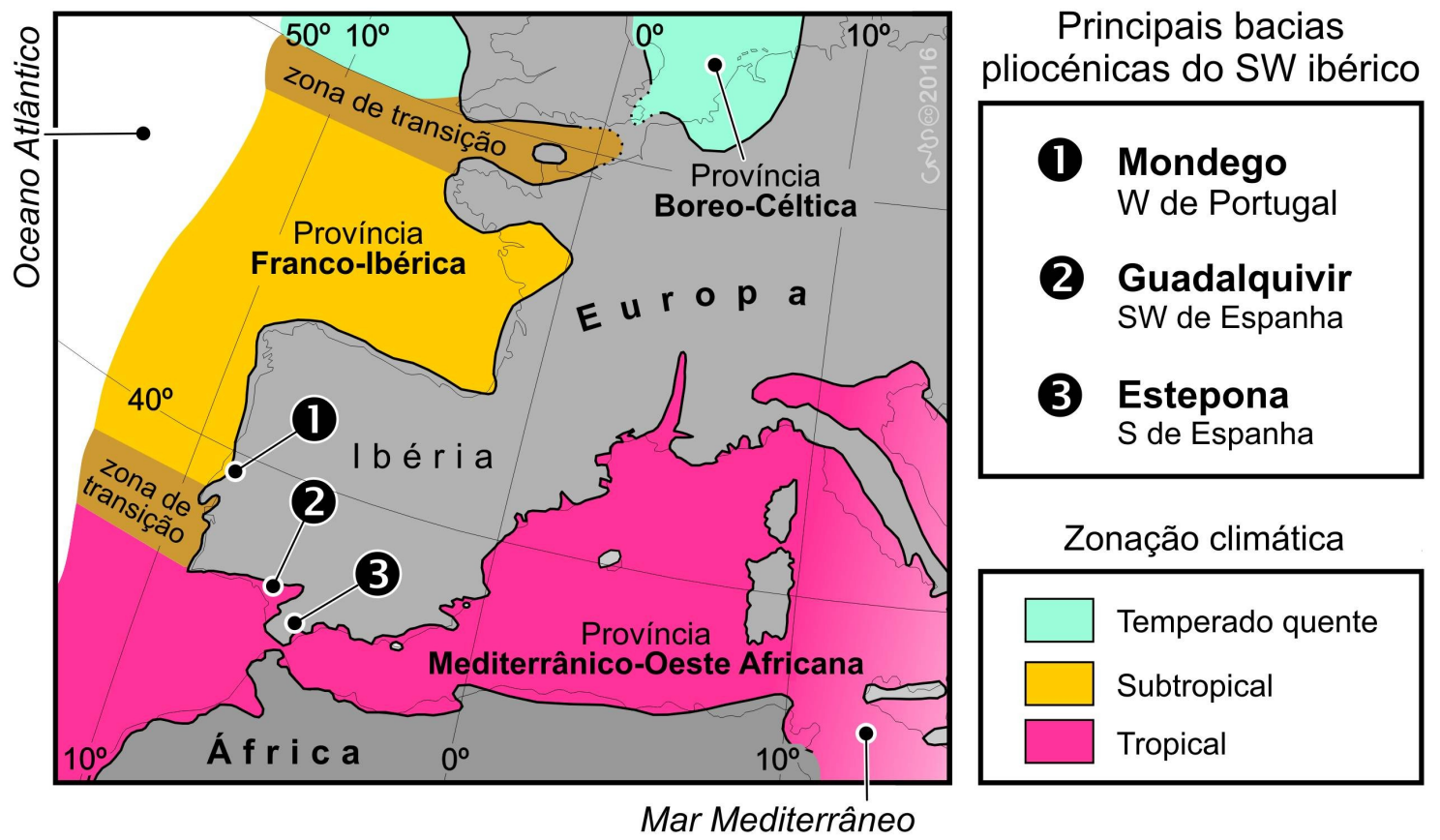

Fig. 6. Paleobiogeografia dos moluscos pliocénicos e zonação climática do Atlântico nordeste e do Mediterrâneo ocidental (Zancleano a Placenciano, ante 3,0 Ma). Fatia temporal correspondente à MPMU1 (vide Fig. 02). Províncias biogeográficas pliocénicas de moluscos Franco-Ibérica e Boreo-Céltica definidas com base no esquema biogeográfico actual de Raffi, Stanley \& Marasti (1985). 1, 2, 3 - Posicionamento paleobiogeográfico das faunas de moluscos representadas pelas associações das principais bacias fossilíferas pliocénicas do SW ibérico (adaptado de SILVA \& LANDAU 2007).

Fig. 6. Palaeobiogeography of the Pliocene (Zanclean - Piacenzian, pre-3.0 Ma) marine molluscs and climatic zonation of the NE Atlantic and W Mediterranean. Time slice corresponding to the MPMU1 (see Fig. 02). Franco-Iberian and Boreo-Celtic Pliocene molluscan biogeographical provinces defined based on the present-day biogeographical zonation of Raffi, Stanley \& Marasti (1985). 1, 2, 3 - Palaeobiogeographic position of the molluscan faunas represented by the assemblages from the main Pliocene SW Iberian fossiliferous basins (adapted from SILVA \& LANDAU 2007).

\subsection{Taxonomia da malacofauna pliocénica portuguesa: ponto da situação}

Em qualquer trabalho paleontológico, a definição e caracterização da paleobiodiversidade representada na associação fossilífera em estudo, a Sistemática e a Taxonomia, são basilares. Assim, desde a sua descoberta, as associações de moluscos pliocénicos marinhos da região de Caldas da Rainha - Marinha Grande - Pombal foram alvo de estudos sistemáticos. Choffat (1889, 1903-04, esta última referência correspondendo a uma nota incluída num trabalho sobre o infralias e o Sinemuriano português), Dollfus \& Cotter (1909, centrado nos Bivalvia), Cox (1936, 1941), Zbyszewski (1959), Brébion $(1971,1974)$ focam, com diferentes graus de detalhe e de profundidade, o estudo sistemático destas associações de fósseis de moluscos, em particular os moluscos gastrópodes. São, porém, os trabalhos de Silva $(1990,1992,1996)$ e, em particular as teses de Silva (1993, 2001), que até ao momento focaram com mais minúcia e profundidade os aspectos relacionados com a definição e caracterização da paleobiodiversidade das associações de fósseis de moluscos pliocénicos da região centro-oeste de Portugal, com um foco particular nos gastrópodes. A Sistemática é um labor fundamental que nunca está verdadeiramente aca- bado, sempre em contínua revisão e actualização, e por isso o tema foi continuado noutros trabalhos aqui elencados para sua mais fácil localização: Silva et al. (2000), Silva (2003), La Perna et al. (2003), Dell'Angelo \& Silva (2003), Silva et al. (2006), Silva \& Landau (2007) e Silva et al. (2011). E, retomado no âmbito do estudo das associações pliocénicas da Bacia de Estepona (Sul de Espanha): Landau \& Silva (2006a,b), Landau et al. (2007) e Landau et al. (2009).

\section{CONCLUSÃO}

Como resultado deste trabalho, do ponto de vista palinológico, foi possível registar a paleobiodiversidade da flora pliocénica identificada; caracterizar a vegetação pliocénica de Pombal, datada com base em nanofósseis calcários e malacofauna (Pliocénico, topo do Zancleano a base do Placenciano, desde aproximadamente 3,61 Ma a 3,0 Ma, ou até mesmo 3,52 Ma, se se tiverem em conta os dados isotópicos disponíveis); definir os ecossistemas existentes e a sua evolução (vegetação palustre subtropical, floresta esclerófila, floresta mista temperada, xerófitos mediterrânicos, gimnospérmicas de média altitude, etc); identificar a ocorrência de condições salobras no início da deposição sedimentar continental (sondagem P1). Estes estudos 
confirmam a correlação palino e climatostratigráfica entre a região de Rio Maior (Bacia de Rio Maior) e a região de Pombal (Bacia do Mondego), um dos sectores mais importantes da Orla Ocidental.

A intrepretação do significado paleoecológico de Coccolithus pelagicus subespécie braarudii permitiu relacionar a presença deste táxon, não a águas oceânicas subpolares mas sim a condições costeiras com afloramento costeiro mais ou menos persistente.

Com base na associação de fósseis de moluscos presente nas camadas fossilíferas de Vale do Freixo conclui-se que, durante o final do Zancleano e o Placenciano ante 3,0 Ma, existia na região em estudo um ambiente marinho de plataforma interna, infralitoral, com uma profundidade inferior a cerca de $24 \mathrm{~m}$, próximo da costa de então e algo protegido da influência directa do oceano. As condições de salinidade seriam marinhas típicas (circa $35 \%$ ) e o substrato arenoso, fino a médio. Relativamente à temperatura das águas superficiais, a associação fossilífera estudada sugere que esta seria subtropical, similar à actualmente registada nas costas da África Ocidental à latitude do Cabo Branco (Mauritânia, $21^{\circ} \mathrm{N}$ ), ou seja: temperaturas médias mensais (TMM) nunca inferiores a $19^{\circ} \mathrm{C}$, com TMM máxima de $23,5^{\circ} \mathrm{C}$ em Setembro e mínima de $19^{\circ} \mathrm{C}$ em Janeiro-Março. Durante este intervalo temporal, algas laminárias fariam parte deste ecossistema marinho infralitoral subtropical e, por isso, existiriam já na costa ocidental ibérica condições de elevada produtividade associada a afloramento costeiro, a upwelling. De um ponto de vista ecostratigráfico, a associação fossilífera de moluscos pliocénicos da Bacia do Mondego, em geral, é correlacionável com a MPMU1 mediterrânica, mas correspondendo a uma unidade biogeográfica distinta, mais setentrional, subtropical, a Província Pliocénica Franco-Ibérica (enquanto a sul desta se estenderia a Província Pliocénica Mediterrânico-Oeste Africana, tropical).

De um ponto de vista biostratigráfico, com base nos elementos actualmente disponíveis, a conjugação dos dados dos nanofósseis calcários e dos moluscos aponta para os níveis fossilíferos marinhos pliocénicos da região de Pombal um posicionamento cronostratigráfico abrangendo desde o topo do Zancleano até à base do Placenciano.

De um ponto de vista paleoecológico, a integração dos dados dos três proxies paleoambientais focados neste trabalho (vegetação continental, por via do seus pólenes e esporos, cocolitóforos e moluscos marinhos) resulta que, efectivamente, durante o intervalo cronológico focado - finais do Zancleano a início do Placenciano - ocorreram em ambientes continentais da região condições de clima subtropical e, em ambientes marinhos, temperaturas das águas superficiais oceânicas também subtropicais.

No tocante às condições oceanográficas vigentes na costa centro-ocidental da Península
Ibérica durante o mesmo intervalo de tempo, as conclusões a que se chegou com base nos dados dos cocolitóforos e dos moluscos são congruentes: há indícios de que ocorreu afloramento costeiro persistente (upwelling) e de que se verificavam condições de significativa produtividade marinha.

\section{AGRADECIMENTOS}

Os autores agradecem aos colegas Manuel Vieira (Shell UK) e Pedro Callapez (Universidade de Coimbra) as suas críticas construtivas, observações e sugestões de enriquecimento deste trabalho expressas aquando da revisão científica do mesmo por eles realizada.

\section{DEDICATÓRIA}

É com profunda alegria e genuína gratidão que os autores dedicam este trabalho ao Professor Doutor António Marcos Galopim de Carvalho, em memória dos longos e frutosos anos de convívio e de trabalho sob sua orientação no Departamento de Geologia da Faculdade de Ciências da Universidade de Lisboa e no Museu de História Natural da Universidade de Lisboa e, também, como prova do reconhecimento pela investigação que desenvolveu no domínio das associações fossilíferas pliocénicas de Bryozoa da região de Pombal.

\section{BIBLIOGRAFIA}

Antunes, M.T. \& MeIN, P. 1981. Vertébrés du Miocène Moyen de Amor (Leiria). Importance Stratigraphique. Ciências da Terra (UNL), 6: 169-188.

BACKMAN, J.; RAFFI, I.; RIO, D.; FORNACIARI, E. \& PALIKE, H. 2012. Biozonation and biochronology of Miocene through Pleistocene calcareous nannofossils from low and middle latitudes. Newsletters on Stratigraphy, 45 (3): 221-244.

BARbosA, B. P. 1983. Argilas especiais de Barracão - Pombal, prospecção, sondagens e cálculo de reservas. Estudos, Notas e Trabalhos do Serviço de Fomento Mineiro, 25(3-4): 193-212.

BARRÓn E.; RIVAS-CARBallo R.; Postigo M. J.; AlCALde - Olivares C.; Vieira M., Castro L.; Pais J. \& VALle-Hernadez M. F. 2010. The Cenozoic vegetation of the Iberian Peninsula. A synthesis. Review of Palaeobotany and Palynology, 162: 382-402.

BrÉBION, PH. 1971. Les Gastéropodes et Scaphopodes du Pliocène portugais. Remarques stratigrafiques et paléogéographiques. Boletim da Sociedade Geológica de Portugal, 17(2-3): 129-138.

BrÉBION, PH. 1974. Nouvelle contribution à l'étude des gastéropodes du Pliocène portugais. Comunicações dos Serviços Geológicos de Portugal, 58: 151-160.

BronN, H.G. 1831. Italiens Tertiär-Gebilde und deren organische Einschlusse. Heidelberg (Karl Groos) (Parte de: Bronn, H.G., 1831. Ergebnisse meiner naturhistorisch-ökonomischen Reisen. Heidelberg \& Leipzig, 2 vols.)

CACHÃO, M. 1989. Contribuição para o estudo do Pliocénico marinho Português. Dissertação PAPCC, Faculdade de Ciências da Universidade de Lisboa. 
CACHÃO, M. 1990. Posicionamento Biostratigráfico da Jazida Pliocénica de Carnide (Pombal). Gaia, 2: 11-16.

CACHÃO, M. 1995. Utilização de Nanofósseis calcários em Biostratigrafia, Paleoceanografia e Paleoecologia Tese de Doutoramento, Faculdade de Ciência da Universidade de Lisboa.

CACHÃO, M. \& MoITA, T. 2000. Coccolithus pelagicus, a productivity proxy related to moderate fronts off Western Iberia. Marine Micropaleontology, 39 (1/4): 131-155.

CAChão, M. \& Silva, C.M. DA 2000. The three main marine depositional cycles of the Neogene of Portugal. Ciências da Terra (UNL), 14: 301-310.

Cardoso, J.L. 1984. O Pliocénico Marinho de Caldas da Rainha e de Pombal. Sedimentologia e Micropaleontologia. Enquadramento Paleogeográfico e Paleoecológico. In: Volume d'hommage au géologue G. Zbyszewski, Paris, Ed. Recherche sur les Civilisations: 155-201.

Carvalho, G.S. \& Colom, G. 1954. Contribuição para o estudo da micropaleontologia dos depósitos detríticos pliocénicos de Portugal. Memórias e Notícias, 37: 37-60.

Carvalho, A.M.G. DE 1961. Note sur les Bryozoaires du Pliocène de Pombal. Boletim da Sociedade Geológica de Portugal, 14: 95-103.

Carvalho, A.M.G. DE 1971. Briozoários do Terciário Português (Cheislostomata) do Neogénico da Orla Ocidental. Lisboa, Publicações do Centro Estratigrafia e Geologia.

Choffat, P. 1889. Observations sur le Pliocéne du Portugal. Bulletin de la Société Belge de Géologie, de Paléontologie et d'Hydrologie, 3: 119-123.

Choffat, P. 1903-04. L'Infralias et le Sinémurien au Portugal. Communicações da Comissão do Serviço Geológico de Portugal, 5: 4-114.

CoX, L.R. 1936. Pliocene Mollusca from Portugal. Memórias e Notícias, 9: 47-75.

CoX, L.R. 1941. New Species of Gastropoda from the Pliocene of Portugal. Memórias e Noticias, 10: 7-12.

CunHA, P.P. 1992. Estratigrafia e sedimentologia dos depósitos do Cretácico Superior a Terciário de Portugal Central a Leste de Coimbra. Tese de doutoramento. Universidade de Coimbra.

Cunha, P.P.; PAIS, J. \& LegoInhA, P. 2009. Evolução geológica de Portugal continental durante o Cenozóico - sedimentação aluvial e marinha numa margem continental passiva (Ibéria ocidental). $6^{\circ}$ Simposio sobre el Margen Ibérico Atlántico MIA09, Oviedo: 11-20.

Dell'Angelo, B. \& Silva, C.M. DA 2003. Polyplacophora from the Pliocene of Vale de Freixo: Central-West Portugal. Bollettino Malacologico, 39(1-4): 7-16.

Diniz, F. 1984a. Apports de la Palynologie à la Connaissance du Pliocène Portugais. Rio Maior: Un Bassin de Référence pour l'Histoire de la Flore, de la Végétation et du Climat de la Façade Atlantique de l'Europe Meridionale. Thèse Docteur d'Etat, Université des Sciences et Techniques du Languedoc, Montpellier.

DINIZ, F. 1984b. Étude palynologique du bassin pliocène de
Rio Maior (Portugal). Paléobiologie continentale, 14(2): 259-267.

DINIZ, F. \& CACHÃO, M. 1987. Le Pliocène de la région de Pombal, rapports bio-chronostratigraphie et paléoécologiques avec le bassin de Rio Maior (Portugal). Resumé, Interim-Colloquium du Groupe de Travail Ecostratigraphie, RCMNS, Montpellier-Barcelona: 29-31.

DinIZ, F. \& MöRnER, N.-A. 1995. The Reuverian/Pretiglian transition in Rio Maior, Portugal. XIV International Congress INQUA, Schriften der Alfred-WegnerStiftung, 2/95: 64.

DINIZ, F. 2003a. Contribuição da Palinologia para o conhecimento do Cenozóico superior de Portugal. Livro de Resumos IX Congresso da Associação Brasileira de Estudos do Quaternário / II Congresso do Quaternário de Países de Línguas Ibéricas / II Congresso sobre Planejamento e Gestão da Zona Costeira dos Países de Expressão Portuguesa,1219 de Outubro, Recife, Brasil: 160.

DinIZ, F. 2003b. Os depósitos detrítico-diatomíticos de Abum (Rio Maior). Novos aspectos paleoflorísticos e implicações paleoclimáticas. Ciências da Terra, núm. especial V: 7, CDRom: A49-A52.

DOllfus, G.F. \& COTTER, J.C.B. 1909. Mollusques tertiaires du Portugal. Le Pliocène au Nord du Tage (Plaisancian). $1^{\text {re }}$ Partie. Pelecypoda. Memórias da Comissão do Serviço Geológico de Portugal, 40: 1-103.

FERREIRA, J. M. 1960. Ocorrência das famílias Lagenidae e Globigerinidae no Pliocénico de Pombal. Comunicações do XXV Congresso Luso-Espanhol para o Progresso das Ciências, Sevilha: 7.

Fauquette, S.; Suc, J.P.; Guiot, J.; Diniz, F.; Fedd, N.; Zheng, Z.; Bessais, E. \& Drivaliari, A. 1999. Climate and biomes in the west mediterranean area during the Pliocene. Palaeogeography, Palaeoclimatology, Palaeoecology, 152: 15-36.

Geisen, M.; Billard, C.; Broerse, A.; Cros, L.; Probert, I. \& Young, J. 2002. Life-cycle associations involving pairs of holococcolithophorid species: intraspecific variation or cryptic speciation? European Journal of Phycology, 37: 531-550.

Gili, C.; Silva, C.M. DA \& Martinell, J. 1995. Pliocene nassariids (Mollusca: Neogastropoda) of centralwest Portugal. Tertiary Research, 15(3): 95-110.

Giraudeau, J. \& Rogers, J. 1994. Phytoplankton biomass and sea-surface temperature estimates from sea-bed distribution of nannofossils and planktonic foraminifera in the Benguela upwelling system. Micropaleontology, 40: 275-285.

Gradstein, F.M.; OGG, J.G.; Schmitz, M. D. \& OGG, G.M., eds. 2012. The Geologic Time Scale 2012. Amsterdam, Elsevier.

HuARD, J. 1966. Étude anatomique des bois de Conifères des couches à lignites Néogènes des Landes. Mémoires de la Société géologique de France, n.s. 105: 5-85.

KownAS, S. 1951. Trzeciorzędowe drewna z Dobrzynia nad Wisłą (Sumário: Fossil Tertiary woods from Dobrzyń). Studia Societatis Scientiarum Toruniensis, 1 : 67-121.

LANDAU, B.M. \& Silva, C.M. DA 2006a. The Early Plio- 
cene Gastropoda (Mollusca) of Estepona, Southern Spain, Part 8: Olividae. Palaeontos, 9: 1-21.

LANDAU, B.M. \& SILVA, C.M. DA 2006b. The genus Scaphella (Gastropoda: Volutidae) in the Neogene of Europe and its paleobiogeographical implications. The Nautilus, 120(3): 81-93.

Landau, B.M.; Houart, R. \& Silva, C.M. DA 2007. The Early Pliocene Gastropoda (Mollusca) of Estepona, southern Spain. Part 7 Muricidae. Palaeontos, 11: 1-87.

LANDAU, B.M.; Silva, C.M. DA \& GILI, C. 2009. The Early Pliocene Gastropoda (Mollusca) of Estepona, southern Spain. Part 8: Nassariidae. Palaeontos, 17: 1-101.

La Perna, R.; Landau, B.M. \& Silva, C.M. Da 2003. The genus Granulina (Gastropoda, Marginellidae) from the Atlantic Iberian Neogene with description of a new species from the Pliocene of Portugal. Iberus, 21(1): $35-42$

LINNAEUS, C. 1758. Systema naturae per regna tria naturae, secundum classes, ordines, genera, species, cum characteribus, differentiis, synonymis, locis, 1. Editio decima, reformata. Holmiae (Laurenti Salvii) [edição fac-símile, British Museum (Natural History), 1956].

Louwye, S.; HeAD, M.J. \& Schepper, S. 2004. Dinoflagellate cyst stratigraphy and palaeoecology of the Pliocene in northern Belgium, southern North Sea Basin. Geological Magasine, 141(3): 353-378.

Manupela, G.; Zbyszewski, G. \& Ferreira, O. DA V. 1978. Carta geológica de Portugal na escala 1/ 50 000. Noticia explicativa da folha 23-A (Pombal). Serviços Geológicos de Portugal, Lisboa.

MARTINI, E. 1971. Standard Tertiary and Quaternary Calcareous Nannoplankton Zonation. In: Farancini, A. (Ed.), Proceedings II Plankton Conference, Roma, 1970, 2: 739-785.

MCIntyre, A. \& BÉ, A.W.H. 1967. Modern Coccolithophoridae of the Atlantic Ocean - I. Placoliths and Cyrtholiths. Deep-Sea Research and Oceanographic Abstracts, 14: 561-597.

Monegatti, P. \& RAfFi, S. 2001. Taxonomic diversity and stratigraphic distribution of Mediterranean Pliocene bivalves. Palaeogeography, Palaeoclimatology, Palaeoecology, 165: 171-193.

Monegatti, P. \& Raffi, S. 2007. Mediterranean - Middle Eastern Atlantic Façade: molluscan biogeography and ecobiostratigraphy throughout the Late Neogene. Açoreana, 552(Supl. 5): 126-139.

MorAIS, J.C. 1936. Geologia e Geografia do Pinhal de Leiria. Memórias e Notícias, 9: 5-46.

MoRAIS, J.C. 1941. Mais alguns fósseis da região do Pinhal de Leiria. Memórias e Notícias, 10: 3-5.

Narciso, A.; Cachão, M. \& De ABreU, L. 2006. Coccolithus pelagicus subsp. pelagicus versus Coccolithus pelagicus subsp. braarudii (Coccolithophore, Haptophyta): a proxy for surface subarctic Atlantic waters off Iberia during the last 200 kyr. Marine Micropaleontology, 59: 15-34.

Nolf, D. \& Silva, C.M. DA 1997. Otolithes de Poissons Pliocènes (Plaisancien) de Vale de Freixo, Portugal. Revue de Micropaléontologie, 40(3): 273-282.
OKADA, H. \& BUKRY, D. 1980. Supplementary modification and introduction of code numbers to the lowlatitude coccolith biostratigraphic zonation. Marine Micropaleontology, 5: 321-325.

PAIS, J. 1987. Macrorrestos de gimnospérmicas dos diatomitos de Rio Maior (Portugal). In: Serrão, J.; Oliveira Marques, A.H. de; Rodrigues, C.M. (Coord.), Da Pré-história à História. Homenagem a Octávio da Veiga Ferreira. Lisboa, Edições Delta: 51-66.

PAIS, J.; CUNHA, P.P.; LegoinhA, P. 2010. Litostratigrafia do Cenozóico de Portugal. In: Neiva, J.M.C.; Ribeiro, A.; Victor, L.M.; Noronha, F. \& Ramalho, M. (Coord.), Ciências Geológicas: Ensino e Investigação, Lisboa, Associação Portuguesa de Geólogos: 365-376.

Pais, J.; Cunha, P.P.; Pereira, D.; Legoinha, P.; Dias, R.; Moura, D.; Silveira, A.B.; KullberG, J.C.; GonZalez-Delgado, J.-A. 2012. The Paleogene and Neogene of Western Iberia (Portugal): A Cenozoic Record in the European Atlantic Domain. Springer Briefs in Earth Sciences. Berlin, Heidelberg, Springer.

Pais, J.; Cunha, P.P.; Legoinha, P.; Dias, R.; Pereira, D. \& Ramos, A. 2013. Cenozóico das Bacias do Douro (sector ocidental), Mondego, Baixo Tejo e Alvalade. In: Dias, R.; Araújo, A.; Terrinha, P.; Kullberg, J.C. (Coord.), Geologia de Portugal, Lisboa, Vol. II: Geologia Meso-cenozóica de Portugal, capítulo III.6., Livraria Escolar Editora: 461-532.

Parente, A.; Cachão, M., Baumman, K.-H.; De Abreu, L. \& FerreirA, J. 2004. Morphometry of Coccolithus pelagicus s.l. (Coccolithophore, Haptophyta) from offshore Portugal, during the last $200 \mathrm{kyr}$. Micropaleontology, 50(Suppl. 1): 107-120.

Postigo-Mujarra, J.M.; Barrón, E.; Manzaneque, F. \& Morla, C. 2009. Floristic changes in the Iberian Peninsula and Balearic Islands during the Cenozoic. Journal of Biogeography, 36(11): 2025-2043.

RAFFi, S. \& Monegatti, P. 1993. Bivalve taxonomic diversity throughout the Italian Pliocene as a tool for climatic-oceanographic and stratigraphic inferences. Proceeding $1^{\text {st. }}$ R.C.A.N.S. Congress, Lisboa, 1992. Ciências da Terra (UNL), Lisboa, 12: 45-50.

Ramos, A.M. 2008. O Plistocénico e o Pliocénico da Plataforma Litoral entre os paralelos do Cabo Mondego de da Nazaré. Tese de doutoramento. Universidade de Coimbra.

Ribeiro, A.; Antunes, M.T.; FerreirA, M.P.; RochA, R.B.; SoARES, A.F.; ZBYszewsKi, G.; MoITINHO DE Almeida, F.; CARvalho, D. DE \& Monteiro J.H. 1979. Introduction à la Géologie Générale du Portugal. Serviços Geológicos de Portugal.

Rocha, A. T. \& FERrEIRA, J. M. 1953. Estudo dos foraminíferos fósseis do Pliocénico da região de Pombal. Revista da Faculdade de Ciências, Lisboa, $2^{\mathrm{a}}$ sér., Ciências Naturais, 3(1): 129-156.

SÁ, A.A.; Meireles, C.; Pereira, Z.; Henriques, M.H.; PEREIRA, D.I.; \& PIÇARRA, J.M. (Tradutores) 2013. Tabela Cronoestratigráfica Internacional. Comissão Internacional de Estratigrafia, v 2013/01.

SILVA, C.M. DA 1990. Moluscos pliocénicos da região de Caldas da Rainha - Marinha Grande - Pombal (Portugal). I. Archaeogastropoda. Fissurellidae. 
Publicações Ocasionais da Sociedade Portuguesa de Malacologia, 15: 1-10.

SILVA, C.M. DA 1991. Significado batimétrico da malacofauna Pliocénica marinha de Vale do Freixo (Pombal, Portugal). III Congresso Nacional de Geologia, Coimbra, 1991: 135.

SILVA, C.M. DA 1992. Moluscos pliocénicos da região de Caldas da Rainha - Marinha Grande - Pombal (Portugal). II. Mesogastropoda. Architectonicidae. Publicações Ocasionais da Sociedade Portuguesa de Malacologia, 16: 1-8.

SiLVA, C.M. DA 1993. Gastrópodes Pliocénicos Marinhos de Vale de Freixo (Pombal, Portugal). Sistemática, Tafonomia, Paleoecologia. Dissertação apresentada no âmbito das Provas de Aptidão Pedagógica e Capacidade Científica, Faculdade de Ciências da Universidade de Lisboa.

SiLVA, C.M. DA 1996. Moluscos pliocénicos da região de Caldas da Rainha - Marinha Grande - Pombal (Portugal). III. Neogastropoda. Conidae. Gaia, 12: $37-43$.

Silva, C.M. DA; LANDAU, B.M. \& MARTinell, J.M. 2000 The genus Solariella (Mollusca: Archaeogastropoda) from the Pliocene of Vale de Freixo, Portugal: Palaeobiogeographic and palaeoclimatic implications. Contributions to Tertiary and Quaternary Geology, 37(3-4): 57-65.

Silva, C.M. DA 2001. Gastrópodes Pliocénicos Marinhos de Portugal. Sistemática, Paleoecologia, Paleobiologia, Paleobiogeografia. Tese de doutoramento. Faculdade de Ciências da Universidade de Lisboa.

SILVA, C.M. DA 2003. Posicionamento estratigráfico da malacofauna pliocénica marinha de Portugal. Implicações paleoceanográficas. Ciências da Terra (UNL), no especial V, CD-ROM: A154-A157.

Silva, C.M. Da; Landau, B.M.; Domènech, R.; MartiNELL, J. 2006. Pliocene Atlanto-Mediterranean biogeography of Patella pellucida (Gastropoda, Patellidae): palaeoceanographic implications. Palaeogeography, Palaeoclimatology, Palaeoecology, 233(3-4): 225-234.

Silva, C.M. DA \& Landau, B.M. 2007. Cenozoic AtlantoMediterranean biogeography of Spiricella (Gastropoda, Umbraculidae) and climate change: Filling the geological gap. The Veliger, 49(1): 1926.

SiLVA, C.M. DA 2010. Glossário etimológico dos nomes das unidades da Tabela Cronostratigráfica. $20 \mathrm{pp}$. (Inédito, acessível em http://paleoviva.fc.ul.pt/ Paleogeofcul/Apoio/Notaetimol.pdf [consultado em 07.03.2016].

Silva, C.M. Da; Landau, B.; Domènech, R. \& MartiNELL, J. 2010. Pliocene Atlantic Molluscan Assemblages from the Mondego Basin (Portugal): Age and Palaeoceanographic implications. Palaeogeography, Palaeoclimatology, Palaeoecology, 285 (3-4): 248-254.

Silva, C.M. DA; Landau, B.M. \& La Perna, R. 2011 Biogeography of Iberian Atlantic Neogene marginelliform gastropods (Marginellidae, Cystiscidae): Global change and transatlantic colonization. Journal of Paleontology, 85(6): 1052-1066.
SUC, J.P. \& ZAGWIJN, W.H. 1983. Plio-Pleistocene correlations between the northwestern Mediterranean region and northwestern Europe according to recent biostratigraphic and palaeoclimatic data. Boreas, 12: $153-166$.

SuC J.P.; Bertini, A.; Combourieu-Nebout, N.; Diniz, F.; Leroy, S.; Russo-ERMOlli, E. \& Ferrier, E. 1995a. Structure of West Mediterranean vegetation and climate since $5.3 \mathrm{ma}$. Acta Zoologica Cracoviensia, 38(1): 3-16.

Suc, J.P.; Diniz, F.; Leroy, S.; Poumot, C.; Bertini, A.; Clet, M.; Bessais, E. \& Ferrier, J. 1995b. Zanclean $(\sim$ Brussumian) to early Piacenzian $(\sim$ earlymiddle Reuverian) climate from $4^{\circ}$ to $54^{\circ}$ north latitude (West Africa, West Europe and West Mediterranean). Mededelingen Rijks Geologishe Dienst, 52: 43-56.

Suc, J.P.; Fauquette, S.; Bessedik, M.; Bertini, A.; Zheng, Z.; Clauzon, G.; Suballoyova, D.; Diniz, F.; QueZel, P.; FeddI, N.; Clet, M.; BeSSais, E.; BachiriI TaOufiQ, N. ; MeOn, H. \& Combourieu-Nebout, N. 1999. Neogene vegetation changes in west European and west circummediterranean areas. In: Agusti, J.; Rook, L. \& Andrews, P. (Coord.), Hominoid Evolution and Climatic Change in Europe, Vol. 1, The evolution of Neogene terrestrial ecossystems in Europe, Cambridge, Cambridge University Press: 378-388.

Teixeira, C. \& ZByszewski, G. 1951. Note sur le Pliocène de la Région à l'Ouest de Pombal. Comunicações dos Serviços Geológicos de Portugal, 32(1): 295 302.

TeIXeIRA, C. 1979. Plio-Plistocénico de Portugal. Comunicações dos Serviços Geológicos de Portugal, 65: 34 $-46$.

Vieira, M.; Castro, L.; Pais, J. \& Pereira, D. 2006. Estudo Palinológico do Pliocénico de Vale do Freixo. Livro de Resumos do VII Congresso Nacional de Geologia, Évora: 673-676.

VIEIRA M. 2009. Palinologia do Pliocénico da Orla Ocidental Norte e Centro de Portugal: Contributo para a compreensão da cronostratigrafia e da evolução paleoambiental. Tese doutoral. Universidade do Minho.

Vieira, M.; PoÇAS, E.; PAis, J. \& PereiRa D. 2011. Pliocene flora from S. Pedro da Torre deposits (Minho, NW Portugal). Geodiversitas, 33(1): 71-85.

ZAGWisN, W. H. 1960. Aspects of the Pliocene and early Pleistocene vegetation in the Netherlands. Mededelingen van de Geologische Stichting, ser C, 3(5): 1 78 .

ZBYSZEWSKI, G. 1959. Etude structurale de l'aire typhonique de Caldas da Rainha. Memórias dos Serviços Geológicos de Portugal, 3 (n.s.): 1-182.

ZByszewsKi, G. \& FerReira, O. DA V. 1967. Découverte de Vertébrés Fossiles dans le Miocène de la Règion de Leiria. Comunicações dos Serviços Geológicos de Portugal, 52: 5-10.

ZBYSZEWSKI, G. \& FARIA, J.B. 1971. Ocorrências de lignito no Pliocénico da Região de Pombal. Boletim de Minas, 7(4): 299-303. 